\title{
The Genes That Carcinogens Act Upon*
}

\author{
F. Anders, M. Schartl, A. Barnekow, C. R. Schmidt, W. Lüke, G. Jaenel-Dess \\ and A. Anders
}

\section{A. Introduction}

Currently in cancer research much emphasis is being placed on mutation [2-4], rearrangement [5], amplification [6-8], and demethylation [9] of oncogenes that are supposed to represent the primary events leading to oncogene activation when carcinogens trigger neoplasia in animals or humans (the reader is referred to ref. [10] for more extensive details on this topic). The data underlying this supposition were mainly derived from experiments performed with tumor cells in vitro. In vivo studies on this issue are rare.

A model which has proven to be suitable for such in vivo studies is Xiphophorus, i.e., a fish genus from Central America known as the platyfish and swordtails [11]. All individuals of this genus carry an oncogene, designated $T u$, which was analyzed by formal genetics long before the viral and cellular oncogenes were identified by methods of modern molecular biology [12 -16]. Our phenogenetic, cytogenetic, and

- This work was generously supported by the Deutsche Forschungsgemeinschaft (SFB 47 "Virologie", 103 "Zellenergetik und Zelldifferenzierung", 118 "Früherkennung des Krebses"), by the Bundesminister fur Forschung und Technologie, by the President of the University of Giessen, 6300 Giessen, FRG, and by the President of the University of Erlangen. 8520 Erlangen, FRG

The present paper supplements that of "The Biology of an Oncogene" published in vol. 28 of this series [1] developmental genetic studies on Xiphophorus, however, have failed so far to detect any structural alterations of the $T u$ oncogene which were expected to occur when the gene switches over from the silent to the tumorigenic state. In contrast, it appears that impairment of the $T u$ oncogene might reduce rather than promote its tumorigenic potential and, therefore, it is difficult to detect.

By means of seven experiments the present study aims to show that the common primary events in the causation of neoplasia in Xiphophorus are changes in the regulatory gene systems controlling the oncogenes rather than changes in the oncogenes themselves.

\section{B. The Oncogene and the Neoplasm Used in This Study}

\section{The Oncogene}

It appears that the genetically identified oncogene $T u$ may mediate neoplastic transformation in poorly differentiated cells of all tissues. The type of tissue in which transformation occurs (for instance in the pigment-cell system) depends on regulatory genes of $T u$. Oncogenes other than $T u$ which were expected to exist in Xiphophorus were not detected by genetic methods (for discussion of this problem see [16]).

From the eleven cellular oncogenes ( $c$ oncs) that were identified molecularly in Xiphophorus (c-erb, c-src, $c$-myc, $c-f g r$, $c$-abl, c-fes, c-myb,c-ras ${ }^{H}, c$-ras ${ }^{K}, c$-sis, $c$-yes) [16] only $c$-src will be taken into con- 
sideration because most of our knowledge comes from this gene. Its inheritance was identified by molecular hybridization of viral src probes with genomic Xiphophorus DNA, and its activity was monitored by the transcript and by the pp60 $60^{c-s r c}$ kinase activity assayed according to Collet and Erikson [17]. The results parallel completely the inheritance and phenotypic expression of the $T u$ oncogene, specified by tumor development $[1,18-20]$.

\section{The Neoplasm}

Out of the 25 different types of neurogenic (neuroblastoma, melanoma, etc.). mesenchymal (fibrosarcoma, reticulosarcoma, etc.), and epithelial (adenocarcinoma. hepatoma, etc.) neoplasms that have been induced and identified in Xiphophorus only melanoma is taken into consideration in this study. This tumor has the advantage over the tumors of other histogenesis in that its development can easily be traced from a single transformed pigment cell detectable by its typical heavy black pigmentation, up to the extreme malignant melanoma that is lethal (Fig. 1).

\section{Results and Discussion}

I. First Experiment: Tumors Induced by Dislocation of Regulatory Genes for the Oncogene in a Germ Line Cell

Information about the crucial event in the causation of this type of hereditary melanoma comes from an X-ray-induced structural chromosome change involving a translocation of the $T u$ oncogene from the $X$ chromosome of Xiphophorus maculatus (platyfish) to an autosome of Xiphophorus helleri (swordtail) and the corresponding $T u$ deletion that took place in meiosis of an $F_{1}$-hybrid female [13] (see Fig. 2 a-d). In its new position (Fig. 2 c) $T u$ is no longer controlled by its formerly linked regulatory genes that act only in the cis position [13]. A powerful regulatory gene nonlinked to Tu that acts in the trans position persisted in the system. Fertilization of the egg with sperm of the swordtail and breeding the
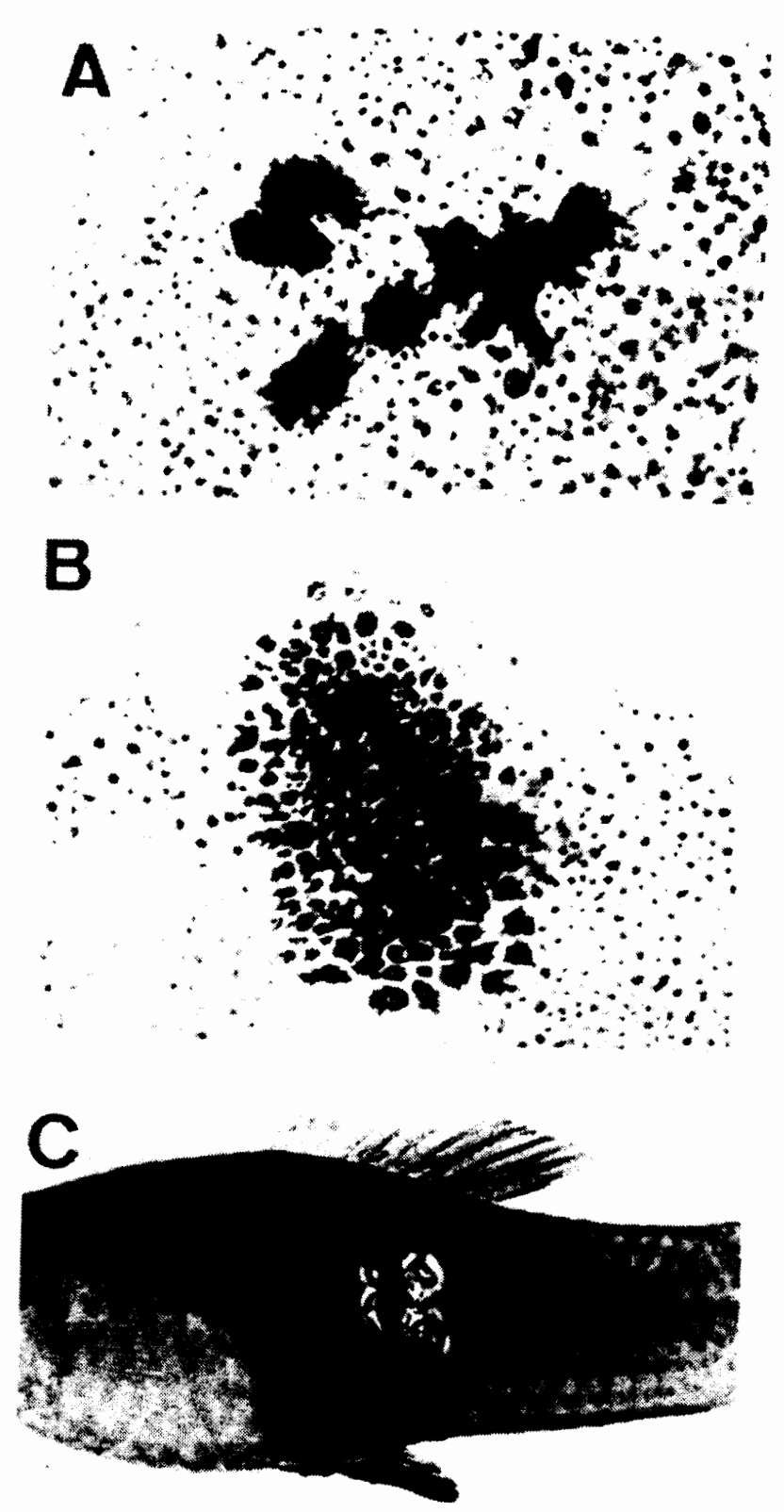

Fig. 1A-C. Development of a somatic mutationconditioned melanoma. A Cell clone consisting of eight transformed melanocytes; $\mathbf{B}$ Clone consisting of some hundreds of transformed melanoblasts and melanocytes; $\mathbf{C}$ Lethal malignant melanoma

mutant using the swordtail as the recurrent parent resulted in offspring in which all animals containing the $T u$ translocation segregated into a $1: 1$ ratio of animals lacking or containing the nonlinked regulatory gene for $T u$.

In both segregants, as a consequence of the lack of the linked regulatory genes. 
a)

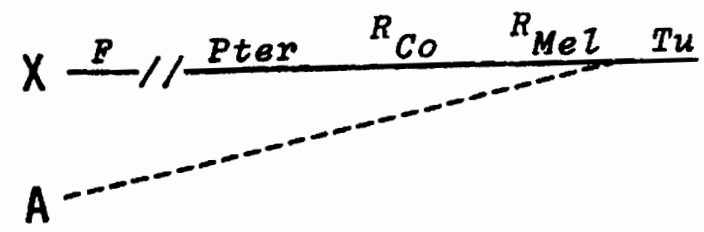

c)

d)

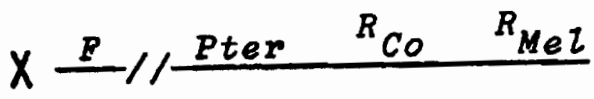

e)

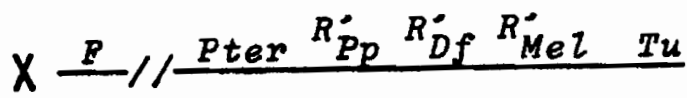

f) $X \stackrel{F}{ } / /$ Pter $^{R_{P p}^{\prime}} R_{D f}^{R}{ }^{R}{ }_{M e l} T u$

Fig. 2a-f. a-c Translocation of the $T u$ oncogene from the $X$ chromosome $(X)$ of $X$. maculatus to an autosome $(A)$ of $X$. helleri and $d$ the respective $T u$ deletion. Note separation of $T u$ from its linked regulatory genes $\boldsymbol{R}_{\mathrm{Mel}}$ and $\boldsymbol{R}_{\mathrm{Co}}$ (see first experiment of this study); e X chromosome of $X$. maculatus that is used in the second experiment (see Figs. 5, 9); $f$ The $X$ chromosome used in the third experiment (see Fig. 10). Note that $e$ and $f$ differ only in the $R_{\text {Mel }}$ locus. $F$, female-sex-determining region; Pter, pterinophore locus. $R_{C o}$ region containing at least 13 compartment-specific regulatory genes such as $R_{P_{p}}$ (posterior part-specific) and $\boldsymbol{R}_{\boldsymbol{D}}$ (dorsal fin-specific); $\boldsymbol{R}_{M e l}$, melanophore-specific regulatory gene; $T u$, oncogene

neoplastic transformation takes place in the pigment-cell precursors of the early embryo. In the segregants lacking both the linked and the nonlinked regulatory genes, neoplastic transformation continues in pigment-cell precursors in all areas of the body, thus forming a "whole body melanoma" (Fig. 3 B) which kills the fish before or shortly after birth. If, however, the nonlinked regulatory gene is present in the system, melanoma development is retarded at the time of birth (Fig. 3C). The fish develop melanoma but may reach sexual maturity, thus providing the possibility to breed by further backcrosses with $X$. hel leri, a stock that continuously produces lethal-melanoma-developing and nonlethal-melanoma-developing embryos. If, furthermore, the regulatory gene is introduced into the system in the homo- zygous state, no $T u$-mediated melanoma develops (Fig. 3A). Fish carrying the Tu deletion chromosome (see Fig. $2 \mathrm{~d}$ ) have a highly diminished potential for the formation of all kinds of neoplasms.

The development of the whole body melanoma in the early embryo reflects the genuine oncogenic effect of the completely deregulated $T u$ on the pigment-cell system. These observations suggest to us that in the early embryo $T u$ normally exerts important functions in cytodifferentiation, which, if $T u$ is completely deregulated, cannot be stopped (see below).

So far we have not tested pp60 $0^{c-s r c}$ kinase activity in the embryos that develop melanoma. However, pp60 $60^{c-s r c}$ kinase activity was measured in the normal developing embryos (Fig. 4) [21]. The activity is detectable from the very outset of cleavage and strongly increases during early organogenesis. While organogenesis morphologically culminates, kinase activity apparently becomes choked, decreases during the growth phase before and after birth to a lower level, and thereafter (not shown in Fig. 4) remains constant at a basic level throughout the whole life of the fish [19]. In adults it was found that pp60 $60^{c-s r c}$ kinase activity is organ specific, with the brain always showing the highest values $[18,19]$. The results suggest that $c$-src activity is related to differentiation and specificity of organs rather than to cell growth. Similar sequences of pp $60^{c-s r c}$ kinase activity during life were found in frogs and chickens (see Fig. 4), indicating that our results are more general rather than fish specific [21].

These genetic, embryological, and molecular biological observations suggest to us that the melanoma-mediating oncogene, irrespective of its appearance as $T u$ or $c$-src, exerts important normal functions as a developmental gene in the early embryo. Moreover, we assume that in normal embryogenesis these functions become switched off or choked by regulatory genes after cell differentiation progresses to organogenesis. If, however, the regulatory genes (i.e. the entire choke in the lethal $T u$ translocation) are lacking, the oncogene continues to exert its early embryo-specific functions which, as an extension of the cellular development in the early embryo, 

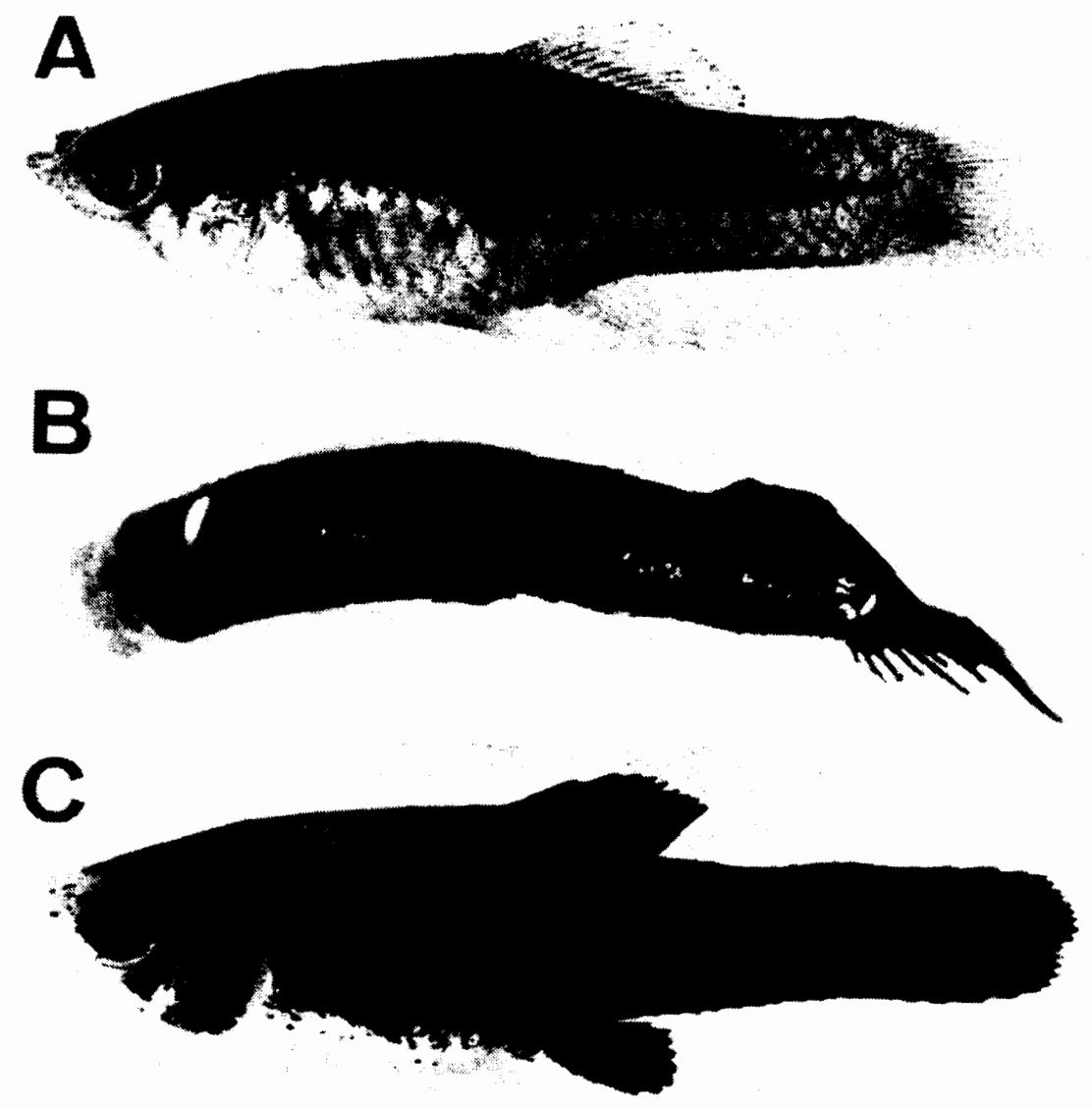

Fig. 3A-C. Backcross hybrids ( $X$. maculatus $\times X$. helleri $X X$. helleri) carrying the $T u$ translocation according to Fig. 2 c. A A nonlinked regulatory gene is present in the homozygous state. There is no tumor; B The nonlinked regulatory gene is lacking. Lethal "whole body melanoma" develops; C One copy of the nonlinked regulatory gene is present. Melanoma develops but the animals reach sexual maturity. A Adult fish. $5 \mathrm{~cm}$ long; $\mathbf{B}, \mathbf{C}$ neonates, $6 \mathrm{~mm}$ long

appear as neoplastic transformation. Support for this idea comes from the high pp60 $60^{c-s c}$ kinase activity that is found in the melanoma of young and adult fish (see second and third experiments). In any case, the crucial event leading to neoplasia in this experiment is the $\mathrm{X}$-ray-induced translocation-conditioned loss of oncogenespecific regulatory genes.

\section{Second Experiment: Tumors Induced} by Crossing-Conditioned Elimination of Regulatory Genes for the Oncogene from the Germ Line

The basic crossing procedure for the production of melanoma-developing Xiphophorus is shown in Fig. 5: Crosses of a wild platyfish female from Rio Jamapa (Fig. 5A) with a wild swordtail male from Rio Lancetilla (Fig. 5 B) result in $F_{1}$ hybrids (Fig. 5C) that develop uniformly in all individuals, with melanomas consisting mainly of well-differentiated transformed pigment cells that are morphologically similar to those of certain spots of the parental platyfish. They occur only in those compartments of the body where the platyfish parent infrequently exhibits the spots, e.g., in the skin of the dorsal fin and the posterior part of the body. In older $F_{1}$ animals, the compartment-specific melanomas combine to form a large benign melanoma. Backerosses of the $F_{1}$ hybrids with the swordtail as the recurrent parent (Fig. 5D) result in offspring $\left(B_{1}\right)$ exhibiting three types of segregants: $25 \%$ of the $\mathrm{BC}_{1}$ (Fig. $5 \mathrm{E}$ ) develop benign melanoma like that of the $F_{1}, 25 \%$ (Fig. 5F) develop malignant melanoma consisting mainly of incompletely differentiated transformed cells which invade other tissues (except for brain, gonads, intestine) and eventually kill the fish, whereas $50 \%$ (Fig. G, H) develop neither spots nor melanomas. Further backcrosses (not shown in Fig. 5) of the fish carrying benign melanoma with the swordtail result in a $\mathrm{BC}_{2}$ that exhibits the same segregation pattern as the $\mathrm{BC}_{1}$. The same applies for further backcrosses of this kind. 

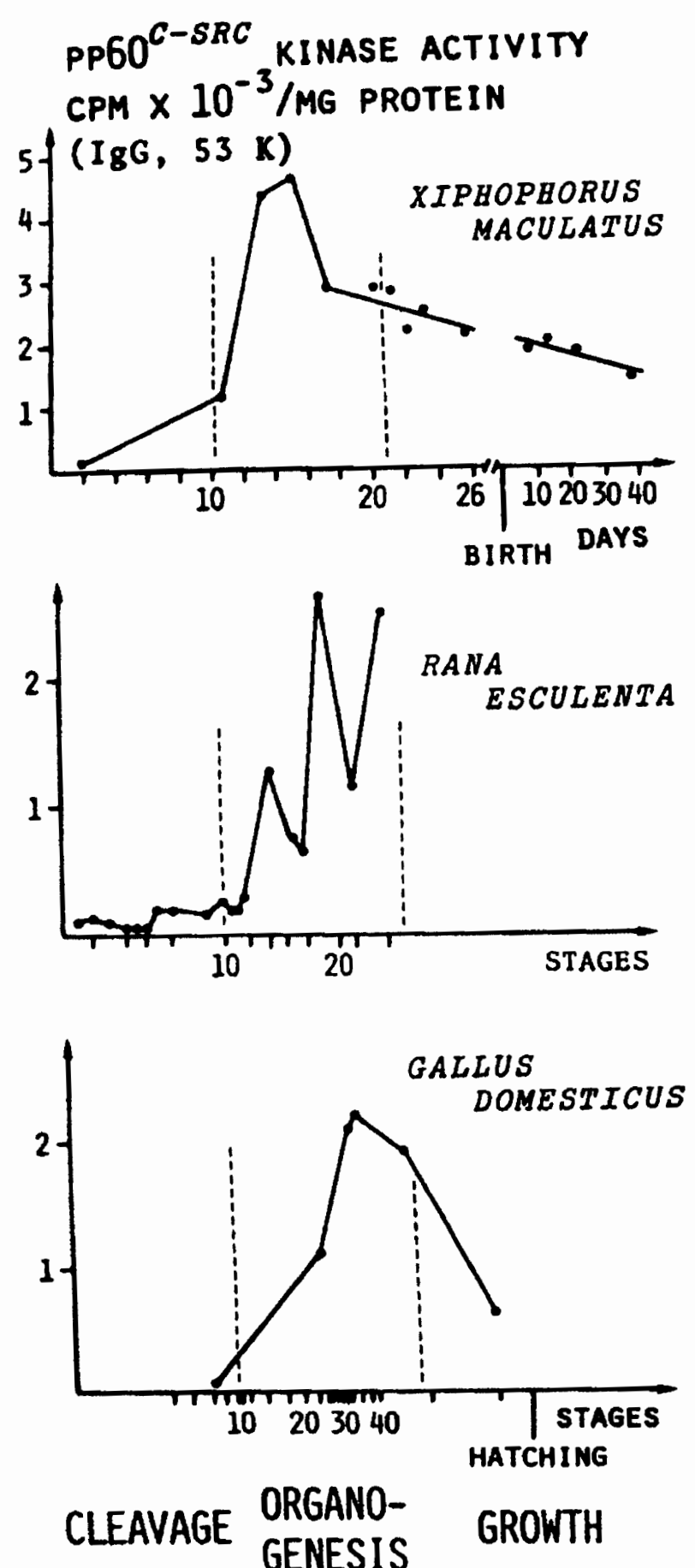

GROWTH

Fig. 4. $p p 60^{\text {issr }}$ Kinase activity during cleavage, organogenesis, and growth. Data from [21]

Backcrosses of the fish carrying the malignant melanoma with the swordtail show a different result: $50 \%$ of the $\mathrm{BC}$ segregants develop malignant melanoma, whereas the remaining $50 \%$ are melanoma free; benign melanomas do not occur. Whenever melanomas occur in these crossing experiments, they develop in both the compartment of the dorsal fin and the compartment of the posterior part of the body.

The results obtained in this crossing experiment (and a large variety of similar experiments) may be explained by the assumption of four prominent genetic components that are involved in melanoma formation or protection from melanoma, respectively. They are contributed by $X$. maculatus (for those contributed by $X$. helleri but not involved in melanoma formation in this crossing experiment, see below) and are normal homozygous constituents of the natural gene pool of the wild platyfish population from Rio Jamapa. Three of the genetic components (see the following points $1,2,3$ ), as was confirmed by about 70 structural changes, are closely linked together at the end of the $\mathrm{X}$ chromosome (see Fig. 2). The fourth (point 4) is autosomally located.

1. The $T u$ oncogene. This gene is apparently responsible for neoplastic transformation. The restriction of neoplastic transformation to pigment cells and to the development of melanoma in the dorsal fin and in the skin of the posterior part of the body comes from other genes.

2 . The regulatory gene $R_{M e l}$. Impairment of this gene ( $\left.R_{M e l}^{\prime}\right)$ specifies the tumorigenic effect of $T u$ to the melanophore system. $\mathbf{R}_{\text {Mel }}$ is a member of a series of tissue-specific regulatory genes which, in the impaired state, determine the histogenesis of the tumors (mesenchymal, epithelial, and neurogenic neoplasms). The mutations of these genes indicate that tissue specificity of neoplasia depends on regulatory genes rather than on oncogenes.

3. The regulatory genes $R_{P_{p}}$ and $R_{D f}$. Impairment of these genes $\left(R_{P p}^{\prime}, R_{D f}^{\prime}\right)$ permits the development of melanoma in the skin of the posterior part of the body $(P p)$ and in the dorsal fin $(D f)$ provided that $\boldsymbol{R}_{\mathrm{Mel}}$ is also impaired. Thirteen compartments of the body (anal fin, tail fin, mouth, eye, peritoneum, meninx, etc.) that have been identified correspond to a series of different regulatory genes $\left(\boldsymbol{R}_{C o}\right.$ in total) which in turn correspond to sites of the body where melanomas may occur (see Fig. 13). 

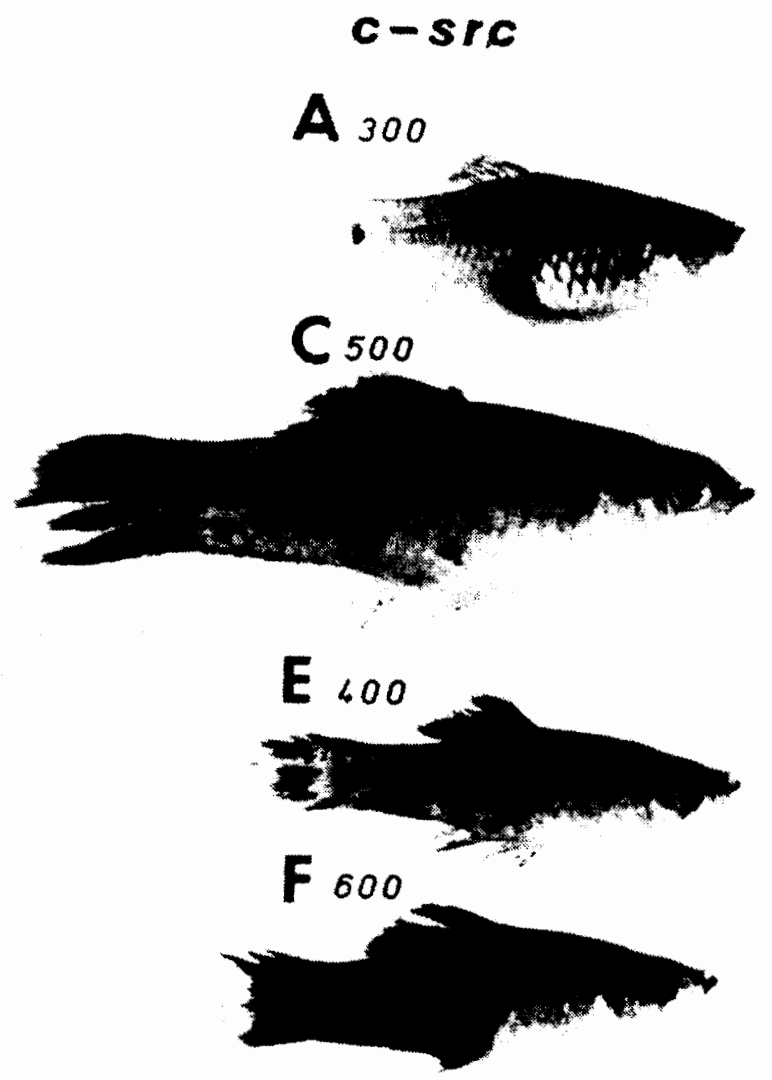

$\mathbf{G}_{300}$

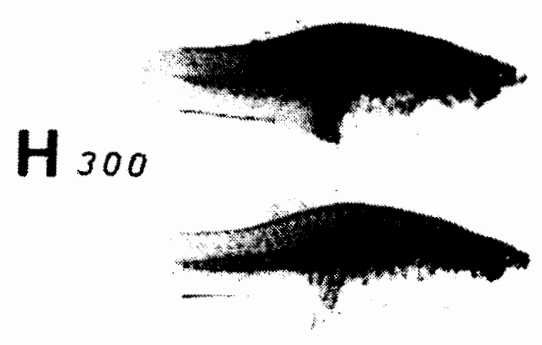

Fig. 5A-H. Crossing procedure for the production of melanoma-developing hybrids of Xiphophorus. A $X$. maculatus from Rio Jamapa (Mexico); some small spots in the skin of the dorsal fin and the side of the body are visible. The spots consist of terminally differentiated, neoplastically transformed pigment cells. $\mathbf{B} X$. helleri from Rio Lancetilla (Mexico). always lacking the spots. $C F_{1}$, developing benign melanoma instead of spots $\left(100 \%\right.$ of the $\left.F_{1}\right)$. D X helleri from $B$ used in the backcross as the recurrent parent. $\mathbf{E}$ Backcross hybrid with benign melanoma ( $25 \%$ of the BC generation). F Backcross hybrid with malignant melanoma (25\% of the $\mathrm{BC}$ generation). G, H Backcross hybrids that do not develop melanoma (50\% of the $B C$ generation). Spots and melanomas (in the posterior part of the body and the dorsal fin) depend on the deregulated $T u$ of the $X$ chromosome shown in Fig. 2 e. Depending on the pterinophore locus (Pter of this chromosome), spotted and tumorous fish ( $\mathbf{A}, \mathbf{C}, \mathbf{E}$ and $\mathbf{F}$ ) exhibit a reddish coloration. pp $60^{c-s r c}$ Kinase activity expressed as counts/min per milligram protein; note basic and excessive activity and correlation between $c$-src expression and $T u$ expression. Data from $[15,19]$ were combined. See Figs. 9 and 10

4. The differentiation gene Diff. This gene is indicated by the $1: 1$ segregation of benign-and malignant-melanoma-bearing fish. If it is present, the majority of the melanoma cells are well differentiated (benign melanoma). If, however, Diff is lacking. the majority of the melanoma cells are poorly differentiated (malignant melanoma).

Additional regulatory genes contributed by the platyfish to the hybrid genome have been identified but are considered only in general in this experiment.

Xiphophorus helleri also contains the $T u$ oncogene and presumably the linked regulatory genes, which. however, are not mutated and thus are fully active. $T u$ and its linked regulatory genes. therefore. are not detectable with the methods used in this experiment. Furthermore, since the linked regulatory genes act only in the cis position. this "oncogene-regulatory-gene complex," contributed by the swordtail, does not significantly influence the expression of the 
platyfish-derived melanoma-mediating $T u$ copy. No Diff and nor any other nonlinked regulatory gene was found in the swordtail that might correspond to those of the platyfish.

The outcome of this crossing experiment suggests the following interpretation: Following crossings and backcrossings according to Fig. 5, the regulatory-gene-carrying chromosomes of the platyfish are replaced stepwise by the homologous chromosomes of the swordtail, resulting in the gradual disintegration of the regulatory gene system for the platyfish-derived $T u$. Thus the $T u$ hybrids spontaneously develop benign melanoma if some regulatory genes such as Diff are still present in the genome and malignant melanoma if the regulatory genes are lacking. If the platyfish-derived $T u$ is lacking, no melanomas occur.

Based on the assumption that the activity of the $\mathrm{pp}^{\mathrm{c}} 0^{\mathrm{c}-\mathrm{src}}$-associated phosphokinase monitors the activity of the $c$-src oncogene, we carried out comparisons between kinase activity, i.e., $c$-src expression, and tumor development, i.e., $T u$ expression. The preparatory work to this study showed that $\mathrm{pp} 60^{c-s i c}$ kinase activity in normal tissues of nontumorous and tumorous fish is tissue specific, with the brain always showing the highest values [18]. It furthermore showed that this activity is elevated in the brain of benign-melanoma-bearing fish, and even higher in the brain of malignant-melanoma-bearing fish. In any case, pp60 ${ }^{\text {c-src }}$ kinase activity varies in both melanoma and the brain in the same direction. Hence, we were able to determine $\mathrm{pp} 60^{c-s r c}$-associated protein kinase activity mainly in brain extracts and relate the activity observed to the expression of $T u$ ascertained by the development of melanoma. The possibility that the differences in kinase activity measured in the fish of different $T u$ genotypes are due to secondary processes in the melanoma appears unlikely. Therefore, the results reflect the actual genetic activity of the $c$-src oncogene in the nontumorous brain tissue of the tumorous and nontumorous fish. For critical evaluation of the methods see refs. $[18,19]$.

As indicated in Fig. 5, the purebred platyfish female (Fig. 5 A) carrying the pop- ulation-specific "Tu-regulatory-gene complex" in both of its X chromosomes, as well as the purebred swordtail and the $\mathrm{BC}$ hybrids lacking this special complex, display the same activity of $c$-src kinase. We interpret this activity to be the basic expression of c-src. In contrast, the melanomabearing hybrids which contain the derepressed $T u$ show an increase in $c$-src activity, with the malignant-melanoma-bearing $\mathrm{BC}$ hybrids displaying the highest activities.

To accomplish the crossing experiment (not shown in Fig. 5) we crossed two melanoma-bearing $B C$ hybrids $(F \times F)$ that exceptionally reached sexual maturity. The resulting $T u / T u$ hybrids $(25 \%$ of the offspring) are of special interest. They show an oncogene dosage effect in both melanoma formation and $\mathrm{pp} 60^{c-s r c}$ kinase activity as compared with the parental BC hybrids [1, 20].

In summary, all experiments of this kind showed a clear-cut correlation between $c$-src expression (measured by $\mathrm{pp} 60^{c-s r c} \mathrm{ki}-$ nase activity) and $T u$ expression (measured by melanoma formation).

Many features that are assumed to be involved in the causation of neoplasia have been found in melanoma of Xiphophorus. About $70 \%$ of the melanomatous cells in cell cultures derived from embryos exhibit at least two pairs of double minute chromosomes (Fig. 6) [22) that might be interpret-

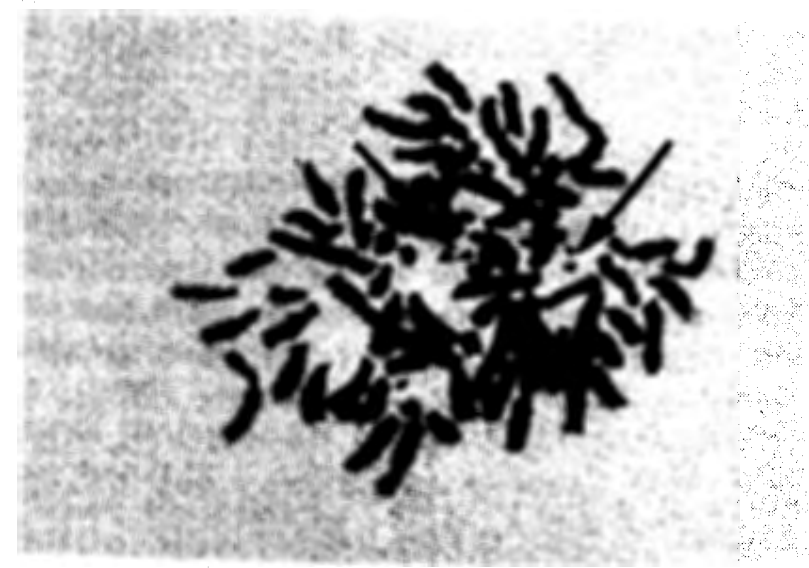

Fig. 6. Metaphase showing double minute chromosomes (DM). DMs were always found in cell cultures derived from melanomatous embryos [22] 

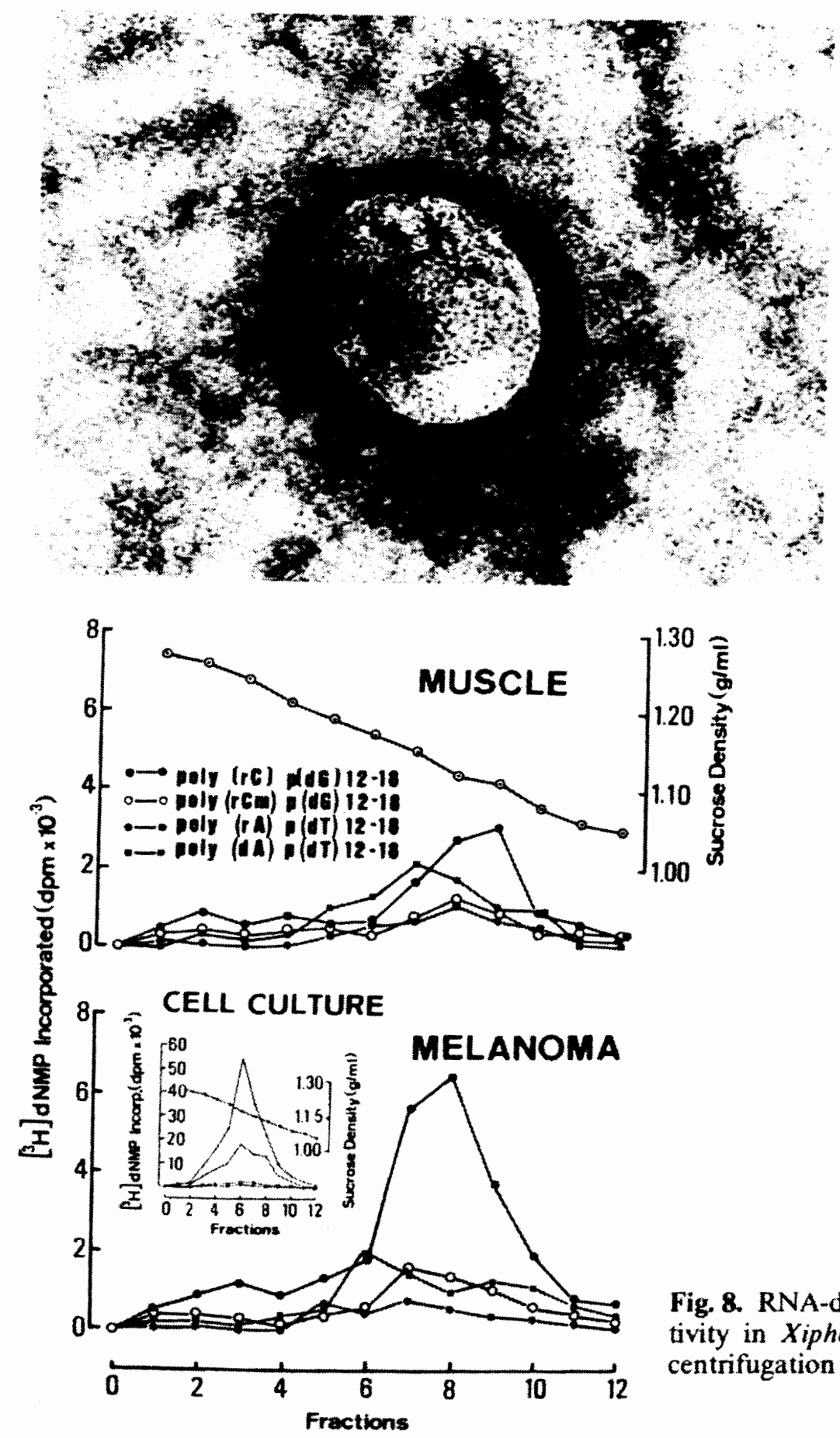

ed as carriers of amplified oncogenes [7, 8]. Virus particles have been found in the melanoma following treatment with bromodesoxyuridine [23]. Following sucrose density centrifugation, in the supernatant of nontreated melanomatous cells of cultures mentioned above, RNA-dependent DNA polymerase associated with particles similar to fish iridovirus [24] (Fig. 7) was found in the density range of $1.15-1.17 \mathrm{~g} / \mathrm{ml}$.
Fig. 7. Virus particle (iridovirus-like [24]). These particles were always found in the supernatant of cell cultures mentioned in the legend of Fig. 6
Fig. 8. RNA-dependent DNA polymerase activity in Xiphophorus. Sucrose density gradient centrifugation of the microsomal pellet
Three to five particles have been counted per grid, which is equivalent to $10^{5}$ particles/ml. RNA-dependent DNA polymerase activity has also been detected in the melanoma tissue and, although three to five times lower, in the muscle (Fig. 8). Activity of many other enzymes, such as tyrosinase [25], lactate dehydrogenase [26, 27], malate dehydrogenase, and pyruvate kinase [27], is changed in the melanoma. 
Table 1. SCE frequency in intestinal cells of Xiphophorus [29]

\begin{tabular}{lllll}
\hline Xiphophorus & $\begin{array}{l}\text { Meta- } \\
\text { phases } \\
\text { scored }\end{array}$ & $\begin{array}{l}\text { Cells } \\
\text { with }\end{array}$ & $\begin{array}{l}\text { Range } \\
\text { SCE (SCE) } \\
\text { cell) }\end{array}$ & $\begin{array}{l}\text { Mean SCE/ } \\
\text { metaphase } \\
\text { (SE) }\end{array}$ \\
\hline
\end{tabular}

$X$. maculatus

Tu/Tu;Diff/ Diff

$X$. helleri

$-1-;-1-$

131

31.9

$0-3$

$0.41 \pm 0.05$

Hybrids carrying melanoma

$\mathrm{F}_{1}$ : benign

$$
T u /-; \text { Diffl- } 153
$$

BC: benign Tul-;Diffl - 113

BC: malignant

$$
\text { Tu/ } ;-1-137
$$

0-3

$0.40 \pm 0.03$

BC hybrids carrying no melanoma

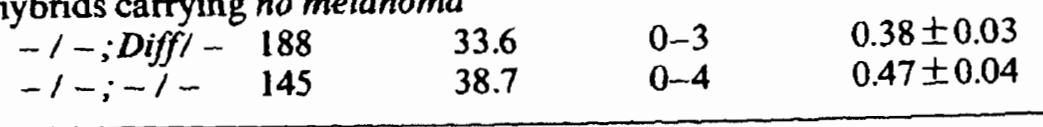

Sister chromatid exchange (SCE) is elevated in melanoma cells [28]. Interestingly, its high frequency is in parallel with that of nontumorous intestinal cells of melanomatous fish, and is low in intestine of the nonmelanomatous fish (Table 1) [29]. This is a striking similarity to the parallels of pp60 6 -src kinase activity measured in the melanoma and in the healthy brain.

These factors and many others not mentioned in this study are certainly important in melanoma formation, but probably none of them is involved in the primary event of tumorigenesis in this experiment. The primary event of tumor initiation in this experiment, without any doubt, happens when the egg and sperm contribute a normal set of oncogenes to the zygote but fail to contribute the adequate regulatory gene systems for control of the oncogenes. The confirmation of this view comes from the final crossing series of this experiment outlined in Fig. 9: Backcrosses of malignantmelanoma-bearing hybrids (Fig. 9A) (i.e., Fig. 5F) with the platyfish (Fig. 9 B) (like those of Fig. $5 \mathrm{~A}$, but containing the $T u$ deletion according to Fig. $2 \mathrm{~d}$ ) result in a quasi $F_{1}$ that segregates in $50 \%$ of animals displaying benign melanoma (Fig. 9C) and $50 \%$ exhibiting neither melanomas nor spots (not shown in Fig. 9). Further backcrosses of the benign melanoma bearing quasi-F, hybrids with the platyfish
Fig. 9A-H. Crossing procedure for the suppression of melanoma in Xiphophorus. A Malignant melanoma-bearing backcross hybrid according to Fig. 5 F. B $X$. maculatus according to Fig. $5 \mathrm{~A}$ as the recurrent parent. C Quasi $F_{1}$-exhibiting benign melanoma. D $X$. maculatus as the recurrent parent. E-H Backcross hybrids (quasi $X$. maculatus) exhibiting spots only. Melanomas and spots depend on $T u$ of the $X$ chromosome shown in Fig. 2 e. See Fig. 5

(Fig. 9D) result in spotted and nonspotted fish that are similar to the purebred platyfish (Fig. 9E-H). Genetically they segregate into those that inherit the capability to develop melanoma after crossings with swordtails and those that do not inherit the capability to develop melanoma (not shown in Fig. 9). The outcome of this final series of backcrosses indicates the stepwise reintroduction of the platyfish chromosomes carrying the regulatory genes for the oncogene into the descendants, and the reconstruction of the original regulatory gene system that suppresses the activity of the oncogene in the platyfish genome.

Fig. 10A-H. Crossing procedure for the production of Xiphophorus hybrids that are sensitive to carcinogens. The procedure is basically the same as that outlined in Fig. 5 (A X. maculatus; $B X$. helleri; $\mathbf{C F}_{1} ; \mathbf{D} X$. helleri). A, C, E, and F exhibit a reddish coloration. c-src, pp60 ${ }^{c-s r c}$ kinase activity. See text 


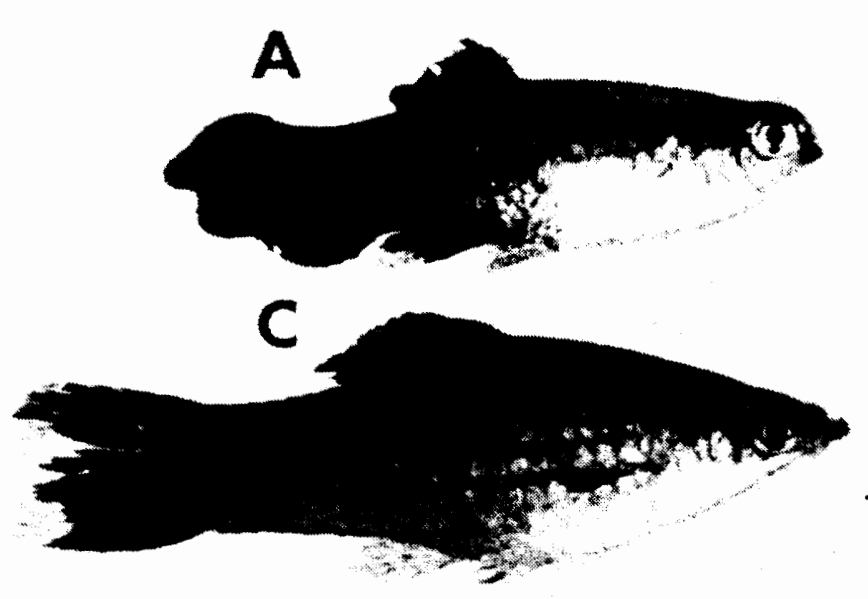

B
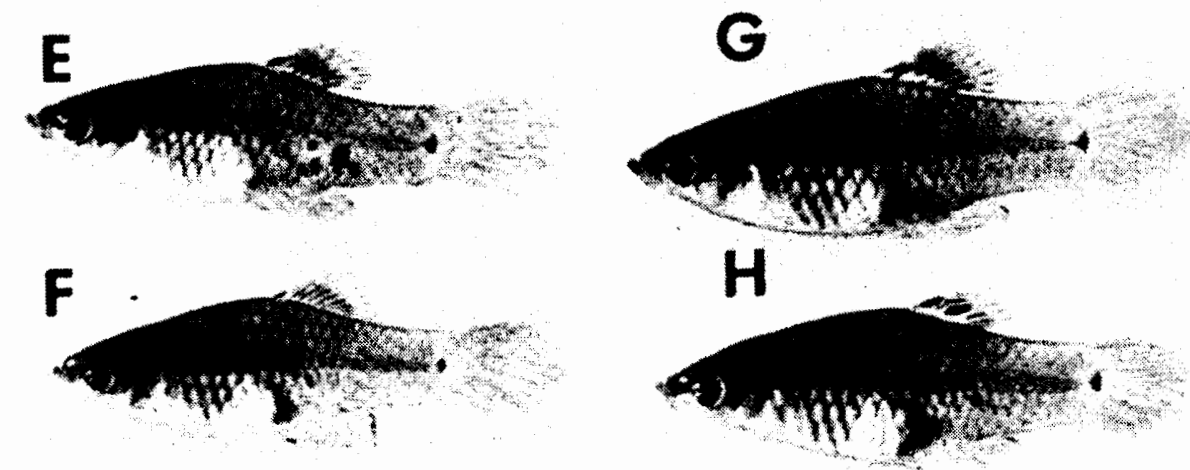

$$
c-s r c
$$
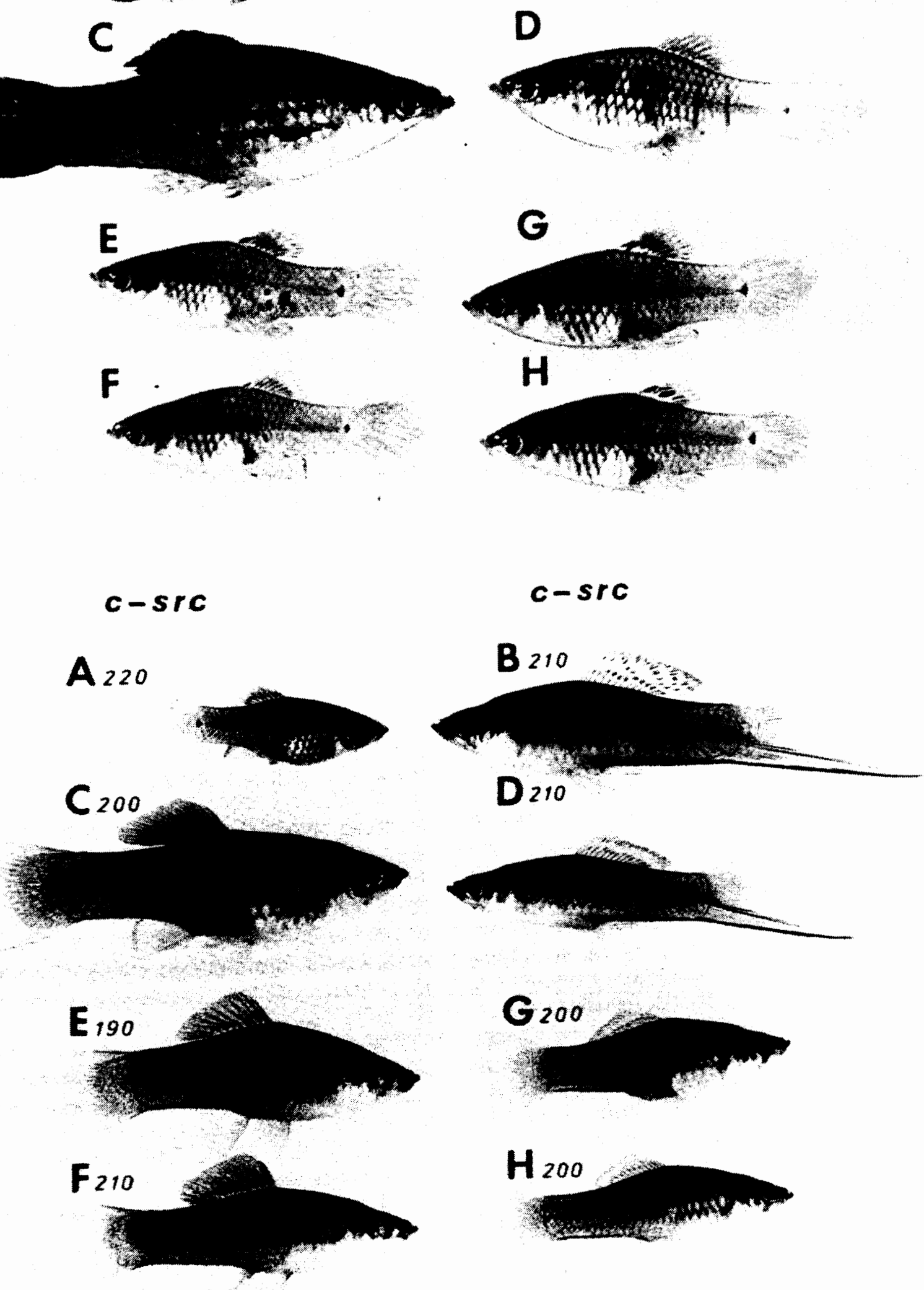

$\sigma_{200}$

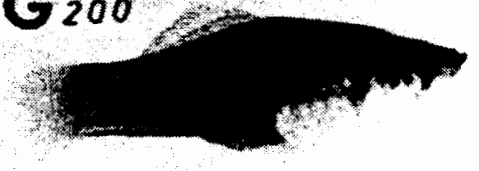

$\mathrm{H}_{200}$

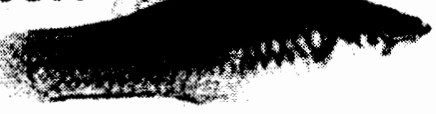




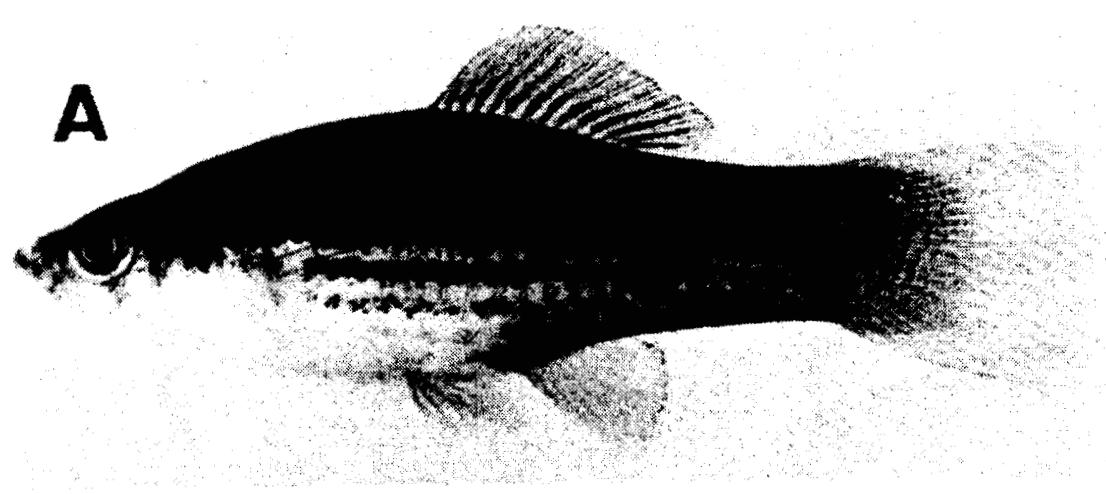

Fig. 11 A, B. Backcross hybrids according to Fig. $10 \mathrm{E}$ and $\mathrm{F}$ after treatment with MNU. A Diffcarrying segregant (identified by an esterase) developing benign melanoma; B Diff-lacking segregant (identified by lack of the esterase) developing malignant melanoma

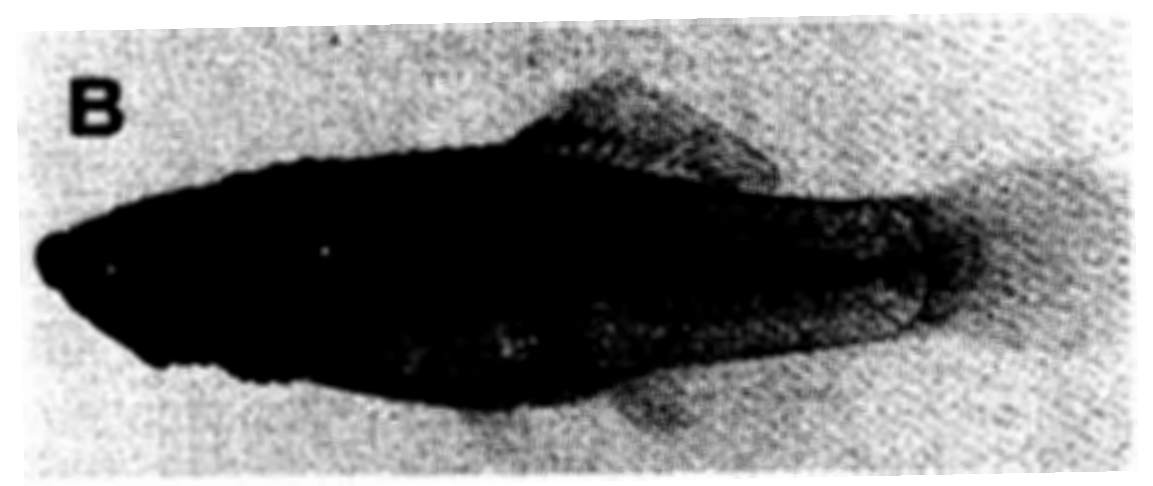

Presumably the oncogene itself remained unchanged during the crossing procedure (Figs. 5,9) that first induced and thereafter suppressed melanoma formation. Carcinogens or tumor-suppressing agents were not required in this experiment. The outcome of the experiment, however, indicates that the experimenter must interfere in the regulatory gene system of the oncogene to be able to induce or suppress melanoma (or any other neoplasm). To examine this idea. we carried out the following experiment.

111. Third Experiment: Tumors Induced by Impairment of Cell-Type-Specific Regulatory Genes for the Oncogene in Somatic Cells

This experiment is based on the two assumptions that (a) the total number of pigment-cell precursors competent for neoplastic transformation is $10^{6}$ (this is the average number in the pigment-cell system of a young fish) and (b) the mutation rate for a given gene in these cells is $10^{-6}$. Then tumor incidence is one (on average $100 \%$ of the treated animals develop one tumor) provided the oncogene is under control of only one regulatory gene. If, however, the oncogene is regulated by two genes, the rate of simultaneous mutations of both regulatory genes in one cell is $10^{-12}$ and the tumor incidence is $10^{-6}$. This calculation shows that if the oncogene is controlled by more than one regulatory gene, it is difficult to succeed in inducing somatic mutation-conditioned neoplasms at a frequency suitable for mutagenesis experiments.

To establish a Xiphophorus strain suitable for mutagenesis studies on a single regulatory gene of the $T u$ oncogene, we replaced the $R_{P p}^{\prime} R_{D f}^{\prime} R_{M e l}^{\prime}$ platyfish X chromosome used so far (Fig. 2e) by the $R_{P p}^{\prime}$ $R_{D f}^{\prime} R_{M e l} T u$ X chromosome (Fig. 2f), which, instead of the impaired $R_{M e l}^{\prime}$, contains the normal $\boldsymbol{R}_{\mathbf{M e l}}$. Crossings were performed according to Fig. 10, which are essentially the same as those described in the first part of the previous experiment (Fig. 5).

Due to the active $R_{M e l}$ that controls the oncogene in the pigment cell system, no melanomas develop in the hybrids. The BC hybrids $E$ and $F$ that correspond to the melanoma-developing $\mathrm{BC}$ hybrids in the former experiment (they can be recognized by a reddish coloration encoded in the pteridine marker gene Pter also linked to the $T u$ oncogene; see Fig. 2) are, however, sensitive to carcinogens and may develop 
Table 2. Tumor initiation (somatic mutation) and promotion (promotion of cell differentiation) distinguished by tester strains of Xiphophorus constructed according to the third and sixth experiments

\begin{tabular}{|c|c|c|c|c|c|c|}
\hline \multirow[t]{2}{*}{ Agents } & \multirow[t]{2}{*}{ Dose } & \multirow[t]{2}{*}{ Period } & \multicolumn{2}{|c|}{ Initiation } & \multicolumn{2}{|c|}{ Promotion } \\
\hline & & & $\begin{array}{l}\text { Survi- } \\
\text { vors }\end{array}$ & $\begin{array}{l}\text { - Tumors } \\
(\%)\end{array}$ & $\begin{array}{l}\text { Survi- } \\
\text { vors }\end{array}$ & $\begin{array}{l}\text { Tumors } \\
(\%)\end{array}$ \\
\hline MNU & $10^{5} \mu \mathrm{g} /$ liter & $5 \times 14$ days $45 \mathrm{~min}$ & 457 & $88(19)$ & 36 & $18 \quad(50)$ \\
\hline ENU & $10^{5} \mu \mathrm{g} /$ liter & $5 \times 7$ days $1 \mathrm{~h}$ & 235 & $21(9)$ & 21 & $2(10)$ \\
\hline Diethylnitrosamine & $45 \times 10^{3} \mu \mathrm{g} /$ liter & $\begin{array}{l}2 \times / \text { week } \\
\text { for } 8 \text { weeks }\end{array}$ & 23 & $2(9)$ & 24 & \\
\hline TPA (in DMSO) & $1 \mu \mathrm{g} /$ liter/day & 10 weeks & 121 & 0 & 23 & $11 \quad(48)$ \\
\hline 4-O-Methyl TPA & $1 \mu \mathrm{g} /$ liter/day & 10 weeks & 20 & 0 & 15 & 0 \\
\hline DMSO & $2 \times 10^{6} \mu \mathrm{g} / \mathrm{liter} / 8$ days & s 10 weeks & 98 & 0 & 12 & $1 \quad(8)$ \\
\hline Diazepam & $500 \mu \mathrm{g} /$ liter/day & 48 weeks & 27 & 0 & 24 & 0 \\
\hline Phenobarbital & $7.5 \times 10^{3} \mu \mathrm{g} /$ liter/day & 10 weeks & 25 & 0 & 11 & $7(64)$ \\
\hline Cyclamate & $10^{6} \mu \mathrm{g} /$ liter & 8 weeks & 28 & 0 & 22 & $12(55)$ \\
\hline & $2 \times 10^{6} \mu \mathrm{g} /$ liter & 8 weeks & NT & NT & 10 & $6(60)$ \\
\hline Saccharin & $5 \times 10^{6} \mu \mathrm{g} /$ liter & 10 weeks & 21 & 0 & 23 & $3(13)$ \\
\hline 5-Azacytidine & $1.25 \times 10^{3} \mu \mathrm{g} /$ liter/day & y 8 weeks & 47 & 0 & 12 & 7 (58) \\
\hline$L$-Ethionin & $500 \mu \mathrm{g} / \mathrm{liter} / \mathrm{day}$ & 8 weeks & 18 & 0 & 16 & 0 \\
\hline Actinomycin D & $20 \mu \mathrm{g} / \mathrm{liter} / \mathrm{day}$ & 8 weeks & 15 & 0 & 10 & 0 \\
\hline Testosterone & $2-20 \mu \mathrm{g} / \mathrm{liter} / \mathrm{day}$ & 24 weeks & NT & NT & 22 & $22(100)$ \\
\hline Methyltestosterone & $2-20 \mu \mathrm{g} / \mathrm{liter} / \mathrm{day}$ & 24 weeks & 113 & 0 & 30 & $30(100)$ \\
\hline 5-Dihydrotestosterone & $2-20 \mu \mathrm{g} / \mathrm{liter} / \mathrm{day}$ & 24 weeks & NT & NT & 11 & $11(100)$ \\
\hline Methylandrostenolone & $2-20 \mu \mathrm{g} /$ liter/day & 24 weeks & NT & NT & 21 & $21(100)$ \\
\hline Estrogen & $2-20 \mu \mathrm{g} / \mathrm{liter} / \mathrm{day}$ & 48 weeks & NT & NT & 5 & 0 \\
\hline Diethylstilbestrol & $2-20 \mu \mathrm{g} /$ liter/day & 48 weeks & NT & NT & 16 & 0 \\
\hline 17-Hydroprogesterone & $2-20 \mu \mathrm{g} / \mathrm{liter} /$ day & 48 weeks & NT & NT & 9 & 0 \\
\hline Progesterone & $2-20 \mu \mathrm{g} / \mathrm{liter} / \mathrm{day}$ & 48 weeks & NT & NT & 8 & 0 \\
\hline X-rays & $1000 \mathrm{R}$ & $\begin{array}{l}3 \times 45 \text { min } / 6 \text { week } \\
\text { interval }\end{array}$ & 805 & $163(20)$ & 45 & $45(100)$ \\
\hline
\end{tabular}

DMSO, dimethylsulfoxide; NT, not tested. Data were compiled from theses of C.-R. Schmidt, A.

Schartl, A. Herbert (Univ. of Giessen)

melanoma after carcinogen treatment. Those BC hybrids carrying the Diff gene (autosomal; identified by a Diff-linked esterase marker gene $[30,31])$ may develop benign melanomas and those lacking Diff may develop malignant ones (see Figs. 1, 11). Crosses between two BC hybrids of the latter genotype were the basis for the establishment of a strain homozygous for the $R_{P p}^{\prime} R_{D f}^{\prime} R_{M e l} T u$ chromosome [32, 33]. Because each of the two copies of the $T u$ oncogene is repressed by its own linked $R_{M e l}$, which acts in the cis position only, the incidence of animals developing melanoma following treatment with carcinogens potentially doubles. These fish are highly suitable as test animals for mutagenic carcinogens in the water (Table 2, see column "Initiation").

In contrast to the crossing-conditioned hereditary melanomas that, due to their multicellular origin [15], cover large areas in the compartments of the body from their very beginning, the carcinogen-induced melanomas appear first as small foci of cells in these compartments (Fig. 1), indicating that they originate from the expected single mutational event in a particular regulatory gene of the oncogene in a particular somatic cell in a particular com. partment of the body.

All purebred and hybrid animals of this experiment display uniform pp60 $60^{c-s n c}$ kinase activity in the brain [19]. This activity seems to represent the basic $c$-src expression like that of the nontumorous fish in the previous experiment (cf. Figs. 5, 10). Following the induction of melanomas and of any other kind of neoplasia, pp60 $60^{\text {-sre }}$ kinase activity in the brain remains unchanged. Kinase activity in the melanomas, however, is heterogeneous, with the malig- 
Table 3. Elevated pp60 6 src kinase activity in Xiphophorus bearing tumors as compared with nontumorous controls

\begin{tabular}{lll}
\hline Tumor & \multicolumn{2}{l}{ Elevation of kinase activity } \\
\cline { 2 - 3 } & In tumors & In brain \\
\hline Hereditary & & + \\
$\quad$ Melanoma, benign $(n=15)$ & + & ++ \\
$\quad$ Melanoma, malignant $(n=13)$ & ++ & \\
Induced & & 0 \\
Melanoma, malignant $(n=2)$ & ++ & 0 \\
Melanoma, malignant & +++ & 0 \\
Melanoma, amelanotic & ++++ & 0 \\
Retinoblastoma $(n=2)$ & +++ & $\mathrm{NT}$ \\
Fibrosarcoma & ++ & 0 \\
Fibrosarcoma & +++ & $\mathrm{NT}$ \\
Fibrosarcoma & +++++ & 0 \\
Rhabdomyosarcoma & + & 0 \\
Rhabdomyosarcoma & ++++ & 0 \\
Epithelioma & ++ & ++ \\
Squamous-cell carcinoma & ++ & 0 \\
\hline
\end{tabular}

NT, not tested nant melanoma showing values that are at least as high as those of the corresponding melanomas of crossing-conditioned hereditary origin. In an induced malignant amelanotic melanoma $\mathrm{pp}^{60-\mathrm{src}}$ kinase activity was even six times higher than that of the brain. As in melanomas, elevated levels of kinase activity were also found in other carcinogen-induced neoplasms such as fibrosarcoma, retinoblastoma, and epithelioma (see Table 3). However, changes in the pp60'-src kinase activity in the brain that are typical in the hereditary tumor-bearing animals were not observed. More studies are necessary to find out whether the elevation of pp60 6 -src activity found in the neoplasms is due to the same impaired regulatory gene that permits the $T u$ oncogene to mediate carcinogenesis.

IV. Fourth Experiment: Transfer of the Regulatory Gene-Dependent Tumorigenic Potential by Genomic DNA

To perform this transfection experiment we used different laboratory stocks of $X$. maculatus as donors. These stocks were uniform with respect to $T u$ and the impairment of the compartment-specific regulatory genes $R_{A p}$ and $R_{P p}$ (see fifth experiment). They were. however, different in the condition of the melanophore-specific regulatory gene
$R_{M e l}$, which was normal, impaired, strongly impaired, or deleted (Fig. 12). Total genomic DNA of the donors was injected into the neural crest region of early embryos (where the pigment-cell precursors originate) of $X$. helleri. This species has excellent potential for expressing a deregulated oncogene (see previous experiments). If a donor containing the normal $R_{M e r} T u$ complex (Fig. 12A) was used, no recipient exhibited transformed pigment cells. If a donor strain was used that carried a $T u$ slightly derepressed in the pigment-cell system by a "weak" mutation of its linked $R_{M e l}$, i.e., $R_{M e l}^{\prime} T u$ (Fig. 12 B), then $0.4 \%$ of the recipients developed colonies of neoplastically transformed cells. If the DNA originated from a strain that carries the $T u$ derepressed to a greater degree, due to a "stronger" mutation of $R_{\mathrm{Mel}}$, i.e.. $R_{\mathrm{Mel}}$ (Fig. 12 C), the incidence of recipients exhibiting transformed pigment cells increased to $2.6 \%$. If, finally, a donor was used in which the $T u$ lacks the $R_{M e l}$ (due to a chromosomal translocation) (Fig. 12D), this incidence increased to $6.3 \%$. DNA from animals carrying additional but rigidly repressed accessory $T u$ copies (not shown in Fig. 12) did not influence the incidence of transformants [34].

Besides the fact that the information for neoplastic transformation, presumably the 
No. of Recipients

\begin{tabular}{|c|c|c|c|}
\hline Phenotype & Chromosomes & Survived & $\begin{array}{l}\text { Showing } \\
\text { Tr cells }\end{array}$ \\
\hline & $\begin{array}{l}\mathrm{X} \frac{R_{\text {Mel } T_{u}}}{\mathrm{Y}} \\
\mathrm{R} \text { Mel Tu }\end{array}$ & 2010 & 0 \\
\hline & $\begin{array}{l}\mathrm{x} \frac{R^{\prime} \text { Met } T u}{R_{\text {Mel }} T_{u}} \\
\mathrm{Y}\end{array}$ & 535 & $2(0.4 \%)$ \\
\hline & $\begin{array}{l}\mathrm{X} \frac{R^{\prime \prime} M e l T_{u}}{\mathrm{R}^{\prime \prime} \text { Mel } T_{u}} \\
\end{array}$ & 1052 & $27(2.6 \%)$ \\
\hline & $\begin{array}{l}\mathrm{A}-\ldots T u \\
\mathrm{~A}-\ldots \mathrm{Tu}\end{array}$ & 1032 & $65(6.38)$ \\
\hline $\begin{array}{l}\text { DNase degraded } \\
\text { DNA of C and D }\end{array}$ & & 710 & 0 \\
\hline
\end{tabular}

Fig. 12A-D. Transfection activity of donor DNA extracted from male gonads of fish differing in $T u$ control by the pigment-cell-specific regulatory gene $R_{M e l}$. Data from [34]. See text

oncogene itself, was transferred via total genomic DNA, it is important to note that the transforming donor DNA did not originate from tumor cells but from the nonneoplastic testes, indicating that oncogenes must not necessarily be changed or amplified in order to acquire the transforming potential. The many oncogene transfection experiments accomplished during the past years by several authors with other systems in which DNA extracts from tumors were used $[2,3,35-37]$, with the expectation that tumor DNA differs from DNA from normal tissues, should be, in our opinion, reconsidered from the viewpoint of repres- sion and derepression of oncogenes exerted by intact and defective regulatory genes. The main factors responsible for neoplasia are, in view of our results on Xiphophorus, not the onc genes, but their regulatory genes.

This view is supported by the fact that the incidence of transformants, i.e., the incidence of transformation events mediated by $T u$, was independent of the number of $T u$ copies in the donor DNA (we tested DNA containing up to eight copies). but was exclusively dependent on the degree of impairment of $R_{\text {Met }}$. In this light it also appears reasonable to assume that $R_{M e l}$, if present, is so closely linked to $T u$ that both $T u$ and $R_{M e t}$ are always cotransferred [34].

Although the donor DNA originated from fish exhibiting different degrees of $T u$ 
expression, the transformed cells of the recipients all looked alike, and the cell colonies were all about the same size. This indicates that growth of the tumor is influenced neither by $T u$ nor by the intact or impaired $\boldsymbol{R}_{\text {Mel }}$.

V. Fifth Experiment: Tumors Induced by Impairment of Compartment-Specific Regulatory Genes for the Oncogene in Germ Line Cells and/or in Somatic Cells

The compartment-specific regulatory genes for the oncogene, designated $\mathbf{R}_{\mathrm{Co}_{0}}$ in total (see Fig. 2), have been studied mainly by means of $\mathrm{X}$-ray-induced germ line mutations that affect one or several sites of the crossing-conditioned melanomas (Fig. 13). These melanomas develop in BC hybrids, for instance (a) in the dorsal fin; (b) in the tail fin; (c) in both the dorsal fin and tail fin; (d) in the anal fin; (e) in the tail fin, dorsal fin, anal fin, mouth tip, and posterior part of the side of the body (mutations of five compartment-specific regulatory genes are involved); (f) in the anterior and posterior parts of the side of the body; (g) in all compartments except for the mouth, belly, eye, dorsal fin, and tail fin; or (h) even in all compartments of the body. The phenotypes of additional combinations of impaired $\boldsymbol{R}_{c_{0}}$ genes have been described previously $[13,15,16]$.

The compartment-specific distribution of these melanomas is inherited according to the segregation of the parental $\mathrm{Tu}$-carrying chromosome, indicating that the respective $R_{C_{0}}$ genes are linked to $T u$, and structural changes of the chromosome have verified that this linkage is very close. At least 14 genes corresponding to 14 different compartments have been identified. They represent regulatory genes that were designated $\boldsymbol{R}_{\boldsymbol{A p}}$ (anterior part), $\boldsymbol{R}_{P_{p}}$ (posterior part), $\boldsymbol{R}_{D f}$ (dorsal fin), $\boldsymbol{R}_{T f}$ (tail fin), etc. in reference to each specific body compartment. Intact $R_{C_{o}}$ genes repress $T u$, and impaired $R_{C o}$ genes permit $T u$ activity. They act in the cis position only, indicating that the compartment-specific regulation of $T u$ exerted by the $R_{C o}$ genes acts at the DNA level.

In the active state the $\boldsymbol{R}_{\text {Co }}$ genes appear to delay the differentiation of pigment cells in the stem-cell stage (S-melanoblasts; see $\boldsymbol{R}_{\text {Co }}$ in Fig. 14). Additional mechanisms that are not understood provide the fish with differentiating pigment cells that mostly escape neoplastic transformation, but very exceptionally may be transformed. If, however, one or several $\boldsymbol{R}_{\boldsymbol{C}}$ genes are impaired by mutation, compartment-specific melanomas develop in the hybrids and are inherited according to Mendelian prediction.

To study whether melanoma can also be induced by impairment of a compartmentspecific regulatory gene in a somatic cell we carried out the following experiment: BC hybrids, which, due to the impairment of the pigment-cell-specific regulatory gene $\left(R_{M e l}^{\prime}\right)$ and of the dorsal-fin-specific regulatory gene $\left(R_{D f}^{\prime}\right)$, develop hereditary melanoma in the dorsal fin only, were irradiated with X-rays. These animals frequently de veloped additional melanomas in other compartments of the body (Fig. 15) which, in contrast to the hereditary melanoma of the dorsal fin, are nonhereditary and develop from small foci of transformed cells in the skin. This indicates a mutational event in a particular compartment-specific regulatory gene in a particular competent pigment-cell precursor in a particular compartment of the body. The oncogene itself that mediates neoplastic transformation probably remained unchanged.

\section{Sixth Experiment: Tumors Induced by Promotion of Cell Differentiation}

The neutral crest cells of Xiphophorus which are, like those of all vertebrates, the precursors of different cell types, start migrating and differentiating at the outset of organogenesis in the embryo (Fig. 14) [38, 39]. Those entering their final locations in the skin and extracutaneous tissues become determined to differentiate to chromatoblasts. These chromatoblasts are the common precursors of all types of pigment cells (chromatophores), including pterinophores, purinophores, and melanophores. Those chromatoblasts committed to differentiate to melanophores give rise to stem melanoblasts (S-melanoblasts). These may reproduce throughout the life of the fish, 

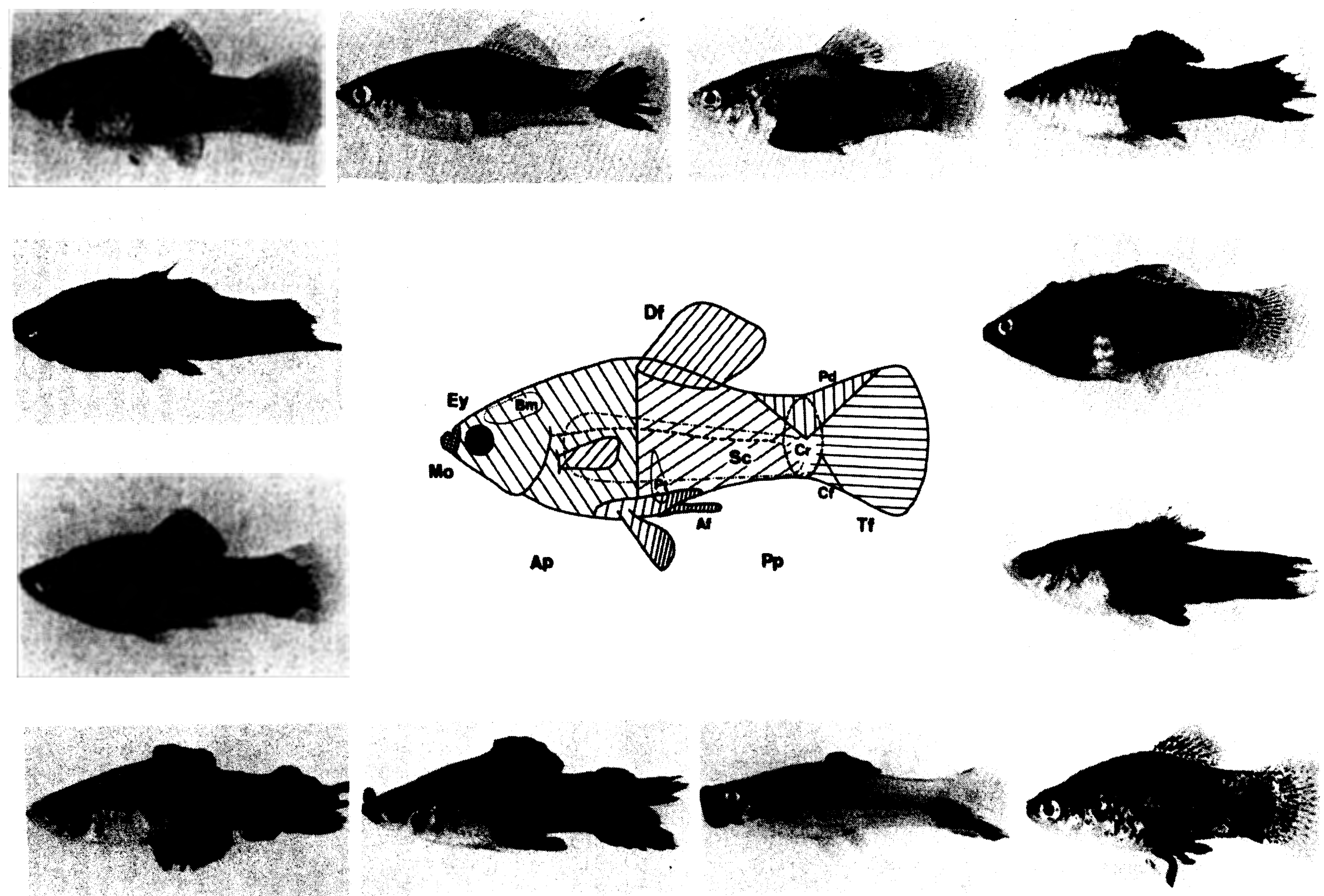

$\tilde{\mathrm{A}}$ Fig. 13. Compartments for the development of melanomas in the fish. Mo, mouth; $E$ y, eye; Bm, brain membrane; $A p$. anterior part: $D f$, dorsal fin: $P t$. peritoneum; $A f$, anal fin; $S c$, spinal cord; $P p$, posterior part; $C r$, crescent region; $P d$. peduncle of the tail fin; $C f$. caudal fin stripe; $T f$, tail fin (see text) 
NORMAL MELANOPHORE

PATTERN
MALIGNANT AND BENIGN

MELANOMA; SPOTS

Different proportions of the different stages of cell differentiation

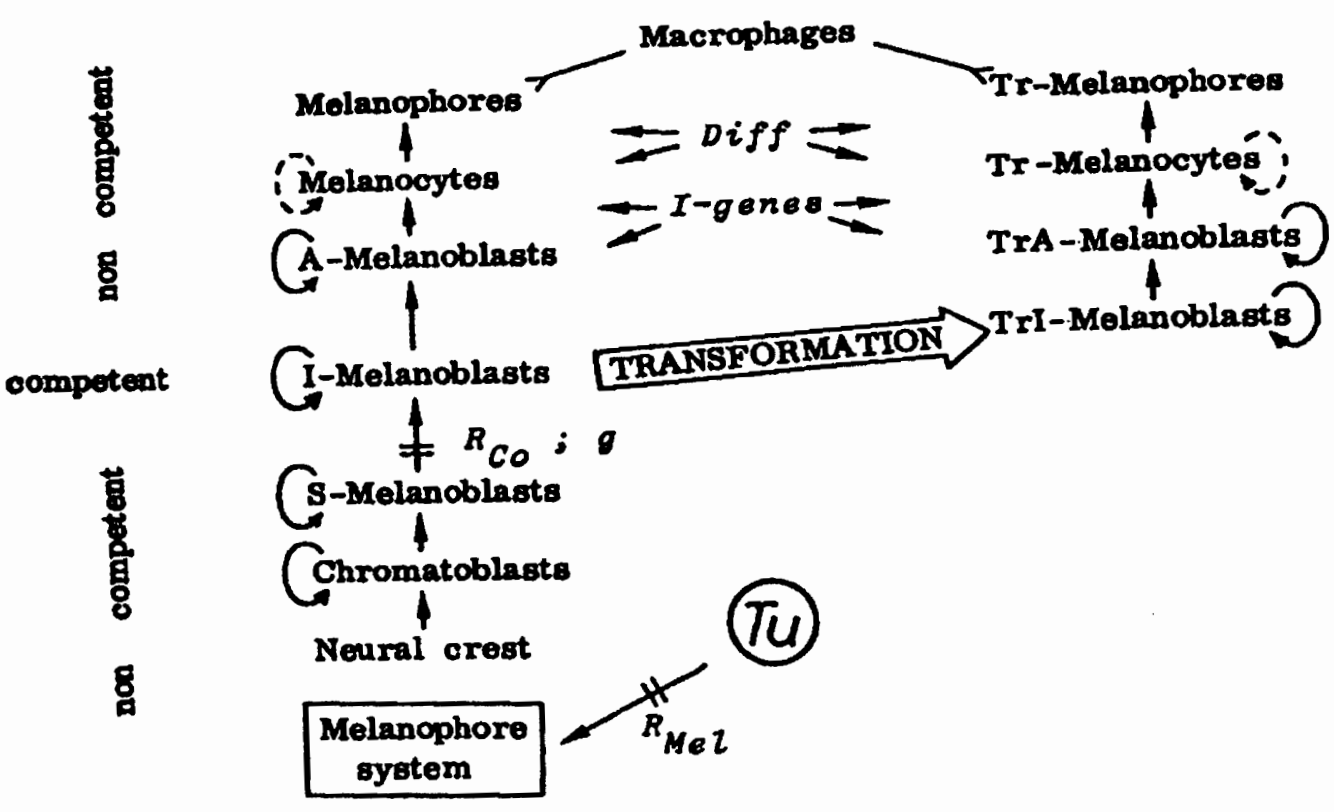

Fig. 14. Schematic presentation of the differentiation of normal and neoplastically transformed pigment cells. $S-, I$, and $A$-melanoblasts are stem, intermediate, and advanced melanoblasts, respectively. The $\operatorname{Tr}$ cells represent the transformed cells. Only I-melanoblasts are competent for neoplastic transformation. $T u$, tumor gene (oncogene); $\boldsymbol{R}_{\mathrm{Mel}}$, regulatory gene for control of $T u$ in the melanophore system; $R_{C o}$, compartment-specific regulatory genes; g. "golden" gene that blocks pigment-cell differentiation; Diff, differentiation gene; l-genes, intensifier genes, which support proliferation of poorly differentiated transformed pigment cells. Macrophages attack melanophores and Tr-melanophores. Modified from [16]

but may also differentiate to intermediate. stage melanoblasts (I-melanoblasts) that continue differentiation to the advancedstage melanoblasts (A-melanoblasts) that can be distinguished from their precursors by their reaction to dopa. These cells differentiate to melanocytes, and these, finally, to melanophores. Genetic, cytological, and ultrastructural studies of the differentiation of the pigment cells have shown that the
I-melanoblasts are the only cells of the system that are competent to undergo neoplastic transformation, i.e., competent to undergo the transforming activity of the $T u$ oncogene [38, 39].

The I-melanoblasts, after being transformed to TrI-melanoblasts (all transformed cells are called $T r$ cells) differentiate to the easily recognizable, proliferating $\operatorname{Tr} A$ melanoblasts. These Tr cells differentiate to the heavily pigmented $T r$ melanocytes, which proceed to the terminal stage of differentiation of the transformed pigment cells, represented by the $T r$ melanophores [15].

We have analyzed several genes that are involved in pigment-cell differentiation. One of these genes is the "golden" gene $\left(g^{+}\right)$, which, if present as a mutation in the homozygous state $(g / g)$, creates an almost complete stop of melanophore differentiation at the stage of S-melanoblasts (see $g$ in Fig. 14). The always present drosopterines become more visible in the skin, thus giving the fish the "golden" coloration.

This $g$ mutation was introduced into the hereditary melanoma-bearing hybrids by 


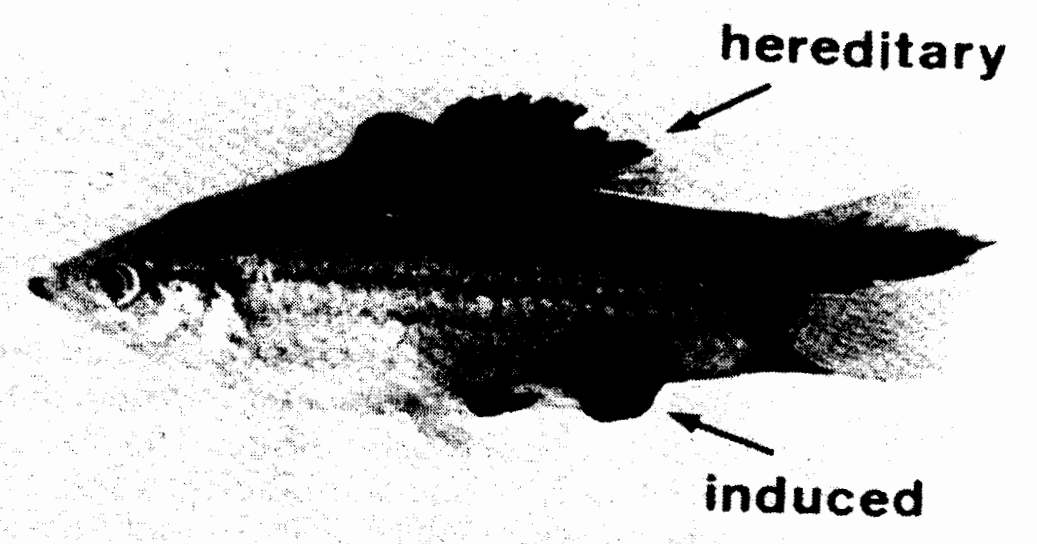

Fig. 15. Fish exhibiting crossing-conditioned hereditary melanoma in the compartment of the dorsal fin and $X$-ray-induced somatic mutation-conditioned melanoma in the com. partment of the posterior part of the body (see $D f$ and $P p$ in Fig. 13)
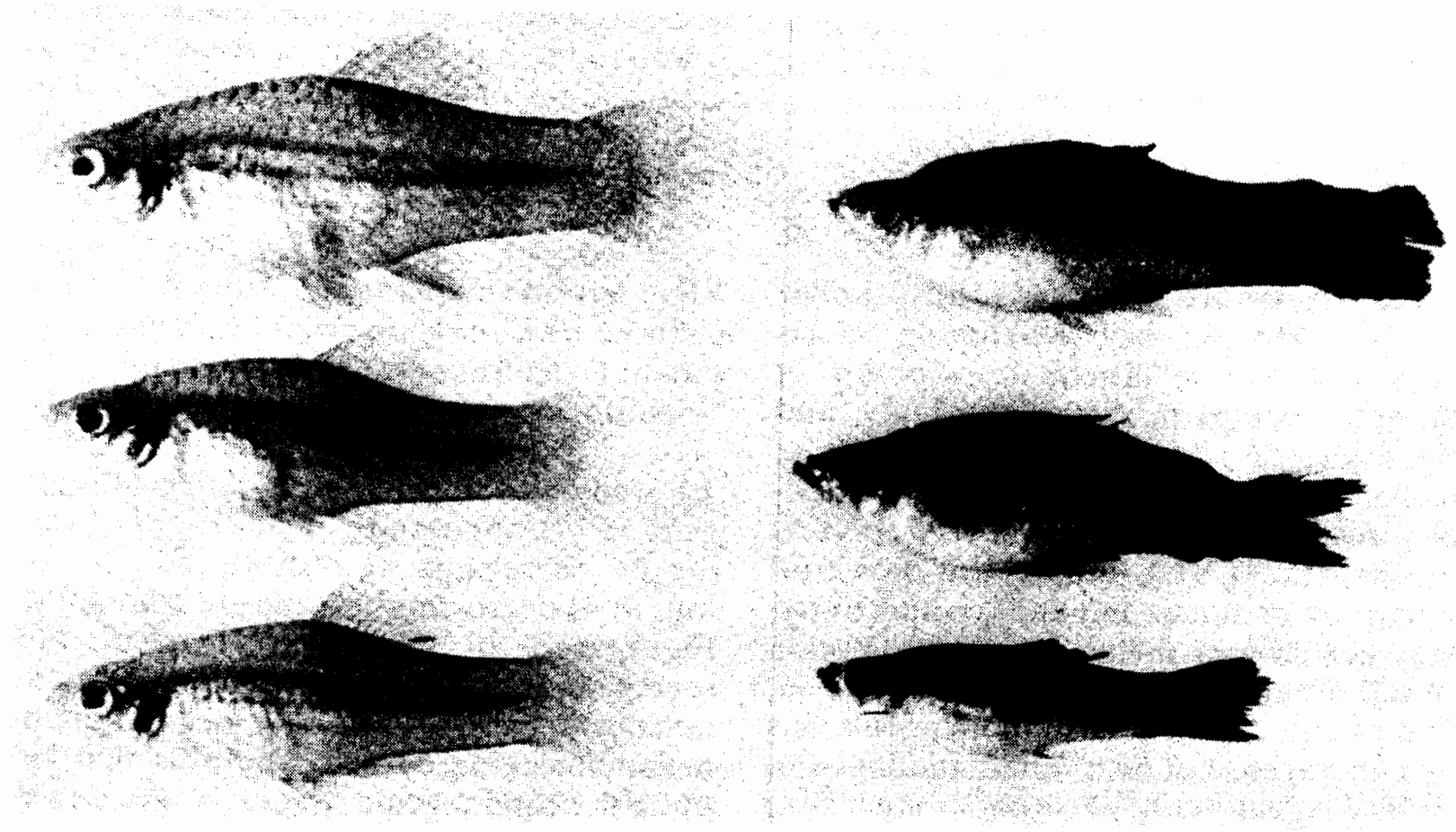

Fig. 16. Littermates that segregate into "golden" $(g / g)$ animals $(l e f t)$ and tumor $\left(g^{+} / g\right)$ animals (right). The $g / g$ animals are protected from melanoma by a block of pigment-cell differentiation in the stage of the stem melanoblasts (see Fig. 14). Following treatment with promoters of cell differentiation (see Table 2) they develop melanoma similar to their heterozygous littermates

introgressive breeding, i.e., by the replacement of the $g^{+}$-bearing chromosome by the $g$-bearing homolog. In animals heterozygous for $g\left(g / g^{+}\right)$the derepressed $T u$ oncogene still mediates melanoma formation (Fig. 16, right). In the littermates that

are homozygous for $g(g / g)$, however, no melanomas develop (Fig. 16, left): The block of differentiation at the stage of the stem melanoblasts exerted by the homozygous $g$-mutation protects the fish from melanoma formation or from the activity of its own derepressed oncogene.

To break this protection mechanism we tested a large variety of mutagenic and nonmutagenic agents. Most of these agents (see Table 2, column "Promotion") promote almost simultaneously the differentiation of large amounts of the noncompetent cells to the competent stage, which subsequently become neoplastically transformed and give rise to melanomas. 


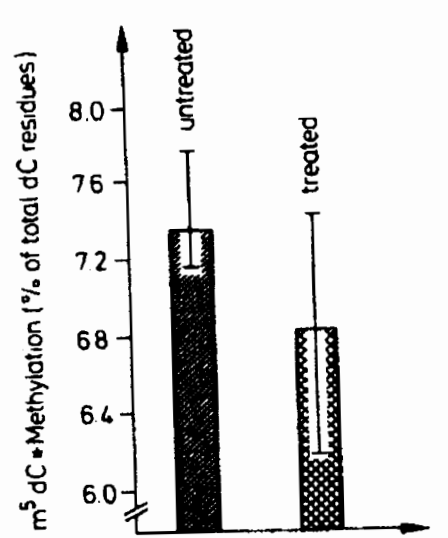

Fig. 17. Decrease of $\mathrm{m}^{5} \mathrm{dC}$ methylation of DNA in Xiphophorus hybrids after treatment with $2.5 \mathrm{mg} /$ liter per day 5 -azacytidine. Fish were treated for 3 months, beginning at birth. HPLC analysis (filling, Supelco 4C-18-DB). Untreated, six animals; treated, five animals [63]

These tumors are morphologically similar to the spontaneously developing melanomas of the $\mathrm{g} / \mathrm{g}^{+}$littermates, develop in the same compartments of the body, and are, similar to all hereditary melanomas, of multicellular origin. X-rays, $N$-methyl$N$-nitrosourea (MNU), and $N$-ethyl- $N$ nitrosourea (ENU), which are powerful mutagens or tumor initiators, respectively, may also trigger melanoma by promotion of cell differentiation. It appears, however, that in this case neither of these agents acts as a mutagen, but as a differentiation-promoting agent such as testosterone, TPA, and cyclamate, which are certainly not mutagens.

The assumption that any somatic mutation. including that of a possible back mutation or suppressor mutation for the $g$ mutation, is not involved in the promoting effect is compatible with the multicellular origin of the melanoma and with the high frequency of the respondents, which, in the case of 17-methyltestosterone, even reaches 100\%. Optimization of the treatment in future experiments will show whether the promoting effect of a certain agent is an allor-nothing effect, as is conceivable on the basis of the concept of this experiment.

Since somatic mutations are probably not involved in the trigger for melanoma development in this experiment, one could speculate that the $g$ mutation undergoes a general modification that brings the function of $g$ close to the normal function of the original $g^{+}$. The promoting effect of 5-azacytidine could be interpreted in this direction. This agent creates undermethylation in the DNA and, as a consequence, presumably gene activation $[9,40,41]$. As shown in Fig. 17, 5-azacytidine, which promotes differentiation, also demethylates DNA of Xiphophorus. More data are required to correlate the removal of the tumor-protecting effect of the $g$-mutation by 5-azacytidine with DNA methylation.

The crucial event leading to neoplasia in this experiment is the promotion of cell differentiation and possibly a more general modification of a gene that is involved in cell differentiation. The oncogene itself probably remained unchanged.

\section{Seventh Experiment: Tumors} Induced by Elimination of a Differentiation Gene from the Germ Line and Impairment of That Gene in Somatic Cells

To study the effect of the differentiation gene (Diff), thousands of melanoma-bearing $B C$ segregants were produced according to the crossing procedure shown in Fig. 5, and all showed a clear-cut $1: 1$ segregation into animals developing spontaneously benign (Fig. 5E) or malignant melanomas (Fig. 5 F). BC hybrids that require the carcinogenic trigger for the development of melanoma also show a clear-cut Diff effect (Fig. 11, see third experiment).

Morphological, histological, cytological, fine structural, biochemical, and molecular studies showed that the majority of the cells of the benign melanoma are well differentiated whereas those of the malignant melanoma are poorly differentiated, and that differentiation of the transformed cells is controlled by Diff $[42,43]$. The most convincing data supporting Diff-dependent control of pigment-cell differentiation in melanoma come from transplantation experiments which have shown that pigmentcell precursors present in the transplants taken from fish carrying the deregulated $T u$ and lacking Diff (material of still tumorfree early embryos of the malignant-mela- 


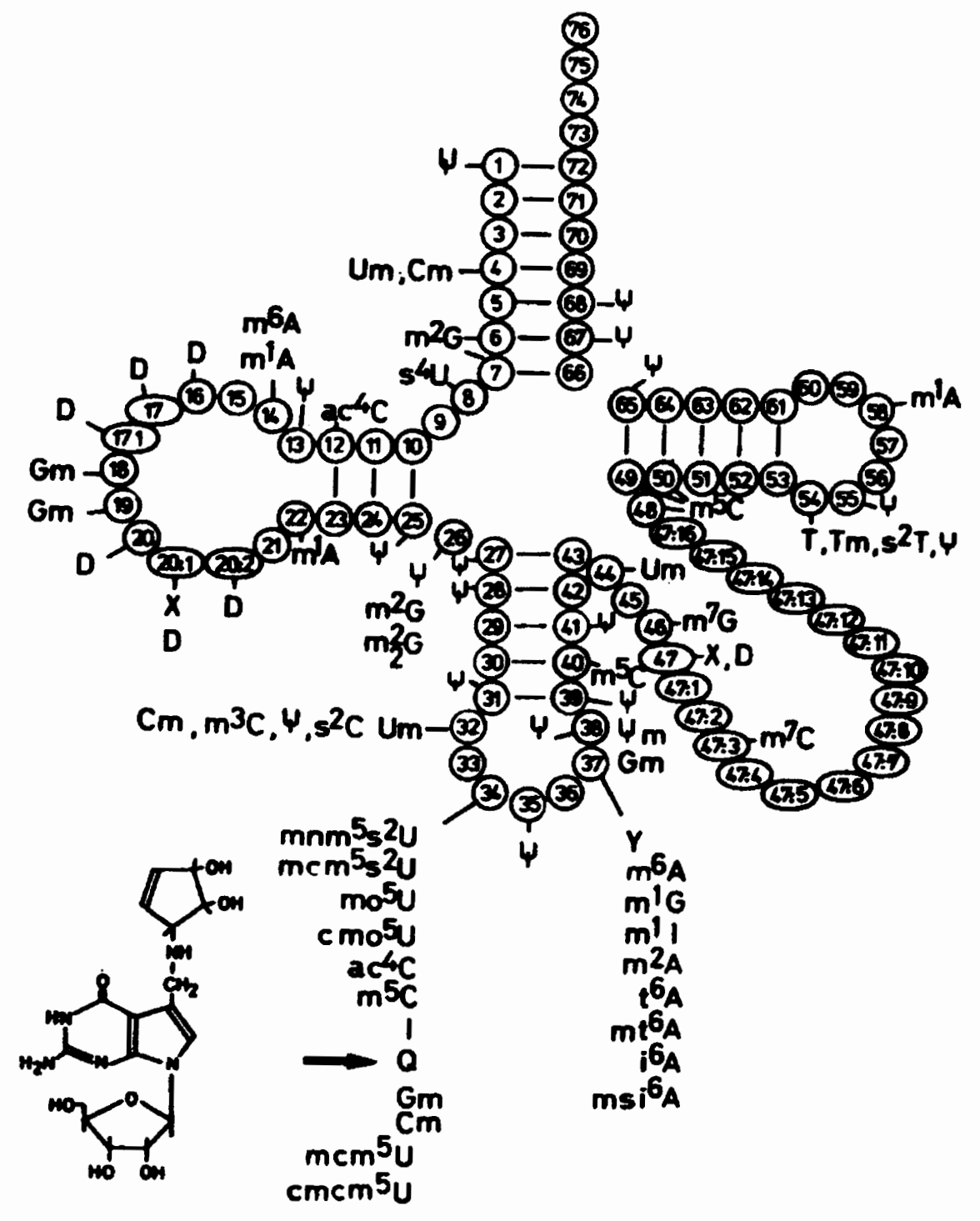

Fig. 18. General cloverleaf structure of the tRNA and positions of modified nucleosides. Bottom left, structure of queuosine $(Q)$ Modified from [49]

noma-developing genotype according to the fish shown in Fig. $5 \mathrm{~F}$ ) become transformed and remain incompletely differentiated if transplanted in to embryos lacking $T u$ and Diff: The resulting animals develop malignant melanoma. If, however, the pigment-cell precursors of the same genotype are transplanted into $T u$-lacking embryos that contain the Diff gene, the cells of the developing melanoma become terminally differentiated and regain their distance regulation: These resulting animals develop extreme benign melanomas which regress and eventually may become removed by macrophages (see [1]).

Further studies on the Diff effect on melanoma in Xiphophorus were stimulated by the experimental results of other laboratories that have focused on the in- volvement of nucleotide modifications of a certain tRNA family in cell differentiation in eubacteria, slime molds, and cell cultures from different vertebrates [43-48]. These tRNAs include tRNA ${ }^{A s n}$, tRNA ${ }^{A s p}$, tRNA $^{\text {His }}$, and tRNA ${ }^{\text {Tyr }}$, which usually contain queuosine (Q) instead of guanosine (G) in the first position of the anticodon (position 34; see arrow in Fig. 18). The $Q$ nucleoside (7-(((4,5-cis-dihydroxy2-cyclopenten-1-yl) -amino) -methyl-7-deazaguanosine) is unique in that its purine skeleton is modified to a 7-deazastructure. Eubacteria synthesize the base queuine de novo whereas vertebrates are supplied with queuine by nutrition or the intestinal flora. Queuine itself is inserted into the nucleotide chain of tRNA by an exchange with guanine. This process is catalyzed by 


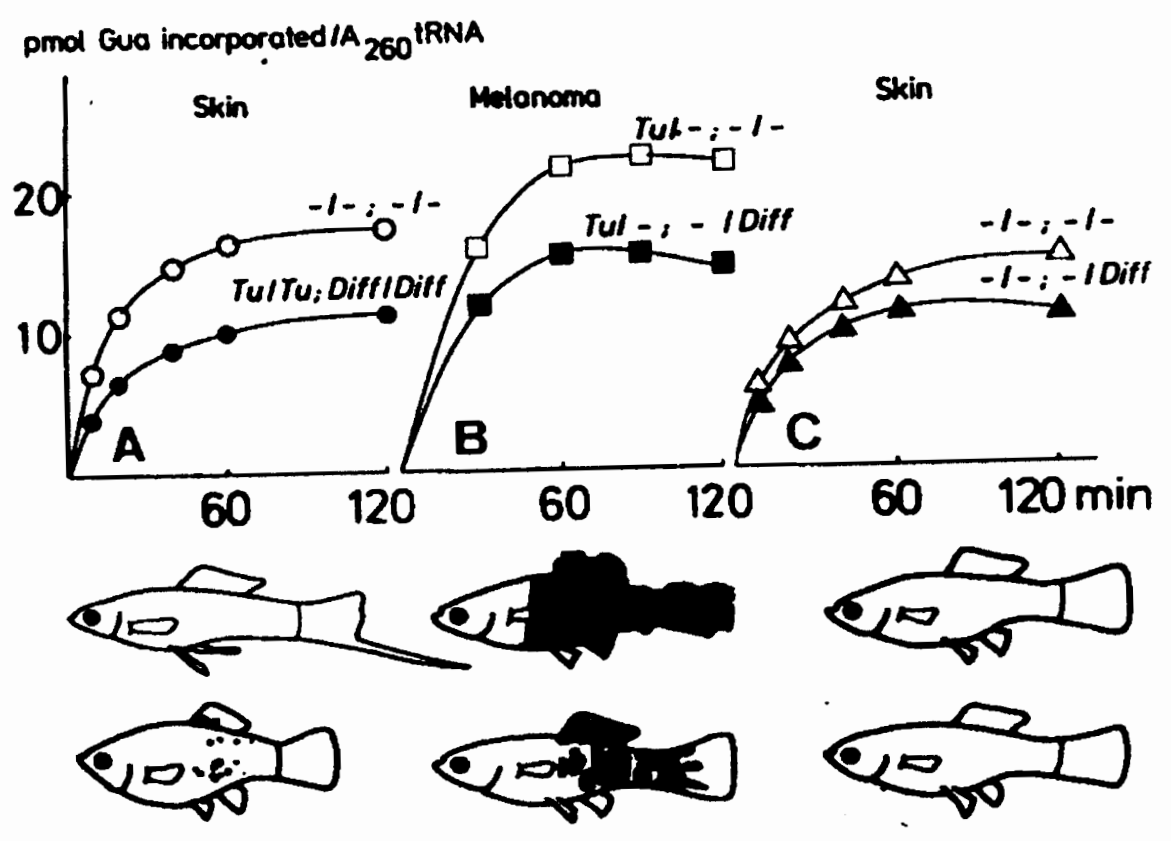

Fig. 19A-C. Incorporation of $\left[{ }^{3} \mathrm{H}\right]$ guanine in position 34 of tRNA for Asp, Asn, His, and Tyr of Xiphophorus catalyzed by tRNA-guanine-transglycosylase (insertase) of $E$. coli. The graphs show the kinetics of the exchange of G34 of IRNA by $\left[{ }^{3} \mathrm{H}\right]$ guanine, a reaction used to evaluate the amount of $\left(\mathrm{Q}^{-}\right)$tRNA [50]. A-C according to the fish shown below the curves. These fish correspond to those shown in Fig. 5. High incorporation of $\left[{ }^{3} \mathrm{H}\right]$ guanine in Diff-lacking animals corresponds to a low content of $Q$, whereas low incorporation of $\left[{ }^{3} \mathrm{H}\right]$ guanine in Diff-containing animals corresponds to a high content of Q. A Skin of purebred Xiphophorus: $O$, X. helleri; $-X$. maculatus. B Melanoma of BC segregants: $\square$, malignant; $\boldsymbol{Q}$, benign. $\mathbf{C}$ Skin of nonmelanomatous BC segregants: $\Delta$, lacking Diff; $\Delta$, containing Diff. Note that comparable Diff-containing animals always have a lower $G$ content and a higher $Q$ content than Diff-lacking ones. Data from $[43,44,51]$

tRNA-guanine-transglycosylases. The more the cells are differentiated, the more replacement of $G$ by $Q$ is observed in position 34.

The method for estimating the $G: Q$ ratio in a given population of the tRNA family consisted of following the replacement of guanine in position 34 by a ${ }^{3} \mathrm{H}$-labeled guanine exerted by a guanine-transglycosylase (insertase) of Escherichia coli $[50,51]$.

The results obtained in Xiphophorus by measurement of $\left[{ }^{3} \mathrm{H}\right]$ guanine incorporation in to the tRNAs of the $Q$ family, differing in the ratio of $G: Q$ in position 34 , are summarized in Fig. 19. The gràphs show the kinetics of the exchange of $G 34$ of the IRNA family by $\left[{ }^{3} \mathrm{H}\right]$ guanine, which is the reaction used to evaluate the amount of $\left(Q^{-}\right)-t R N A$. The fish genotypes and phenotypes are identical to those shown in Fig. 5.

In accordance with the findings of many investigators working with other differentiation systems [52], $\left[{ }^{3} \mathrm{H}\right]$ guanine incorporation is high in tRNAs from malignant melanomas that consist predominantly of poorly differentiated cells: In contrast, the incorporation is lower if the tRNAs are derived from benign melanomas that consist predominantly of well-differentiated cells. Therefore, $t R N A s$ of malignant melanomas have a higher amount of $G$ in place of $Q$ than those of the benign melanomas (Fig. 19 B).

To decide whether the distinct difference in $G: Q$ ratios between benign and malignant melanoma is Diff dependent or represents an epiphenomenon of benignancy and malignancy, the skin of nontumorous littermates that segregate into animals carrying Diff and lacking Diff like the tumorous fish in a $1: 1$ ratio was used for analysis (Fig. 19C). The Diff-lacking segregants always had higher amounts of Q-lacking tRNA than the Diff-carrying animals. The skin of the parent animals used 

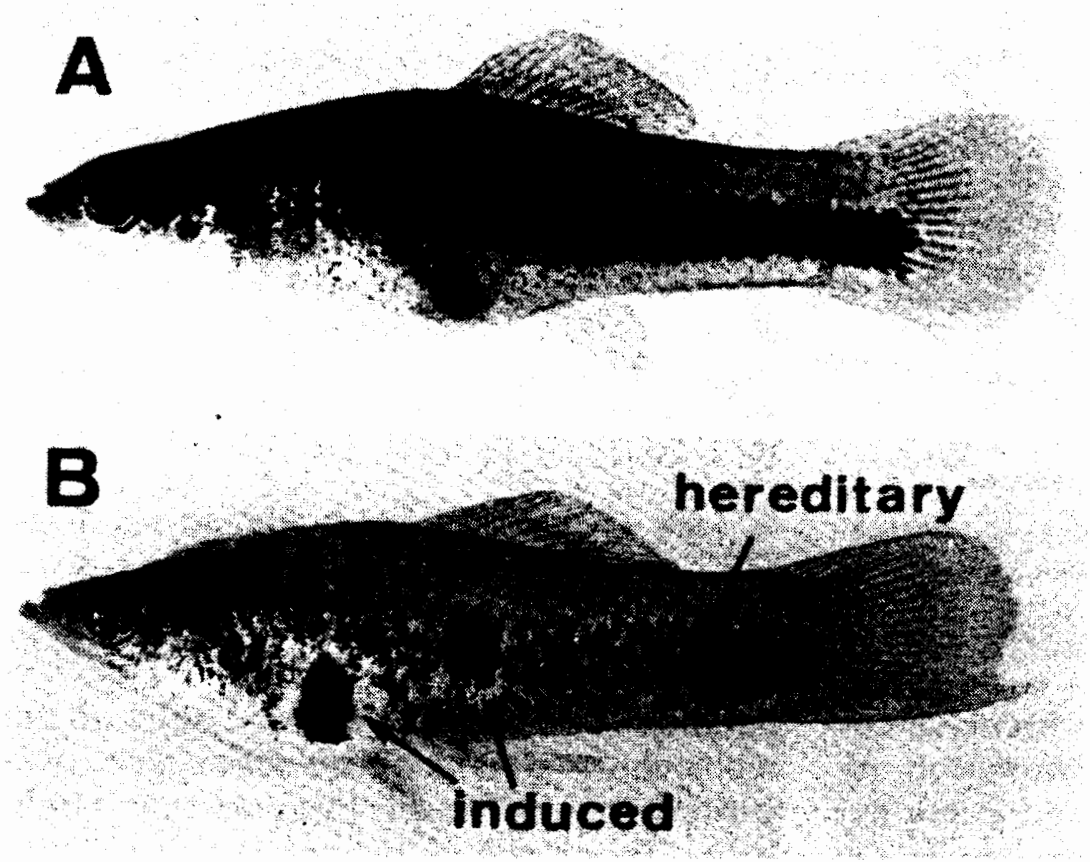

Fig. 20A,B. Development of induced somatic mutation-conditioned malignant melanomas on a crossing-conditioned superficial hereditary melanoma. A Untreated fish; B Fish treated with $\mathrm{X}$-rays. It is assumed that the induced melanomas are due to an impairment of the differentiation gene Diff in a pigment-cell precursor each for the initial crosses showed the same differences (Fig. 19A): X." helleri, which lacks the Diff gene, has a high $\left[{ }^{3} \mathrm{H}\right]$ guanine incorporation (i.e., is $G$-rich) whereas $X$. maculatus, which contains the Diff gene, has a lower $\left[{ }^{3} \mathrm{H}\right]$ guanine incorporation. From these results we suggest that the difference of $G: Q$ ratios between benign and malignant melanoma are not epiphenomena of benignancy and malignancy, but are closely related to the primary effect of the Diff gene.

The differences in the functional properties of Q-eontaining and Q-lacking tRNAs require further elucidation. The (Q)tRNAs have been suggested to prefer codons NAU to NAC, whereas the Q-lacking tRNAs read NAC and NAU equally well [46]. This may be an important mechanism in the regulation of transiation. For eukaryotic tRNA ${ }^{\text {Tyr }}$ it has been shown that the Q-lacking species reads a terminator codon, probably UAG. Therefore the Q-lacking and Q-containing tRNAs of vertebrates might select mRNAs for translation by a regulatory mechanism similar to that of termination transcription control (see discussions in ref. [51]).

If benignancy depends on the presence of a single copy of Diff and malignancy on the lack of this copy then it should be possible to induce easily somatic mutation- conditioned malignant melanoma in the area of germinal-conditioned benign melanoma. For this purpose we treated superficial benign melanoma with $\mathrm{MNU}$ or $X$-rays and observed the development of focal malignant melanoma in the area of the benign melanoma (Fig. 20). This is not to say that the benign melanoma changes to the malignant state. In contrast, the somatic mutation-conditioned malignant melanoma develops independently from the already present germ-line-conditioned benign melanoma. The induced malignant melanoma, however, competes with the hereditary benign melanoma for pigmentcell precursors. As a consequence of this competition the focal malignant melanomas are surrounded by a halo-like zone that is sparsely polulated by the cells of the benign melanoma.

This experiment shows once more that the genes that carcinogens act upon if they trigger neoplasia are not necessarily the oncogenes themselves, but their regulatory genes in the broadest sense.

\section{Conclusions}

In our Xiphophorus model we have not found any genetic change of the Mendelian inherited oncogene $T u$ that might lead to neoplasia, although one would expect this 


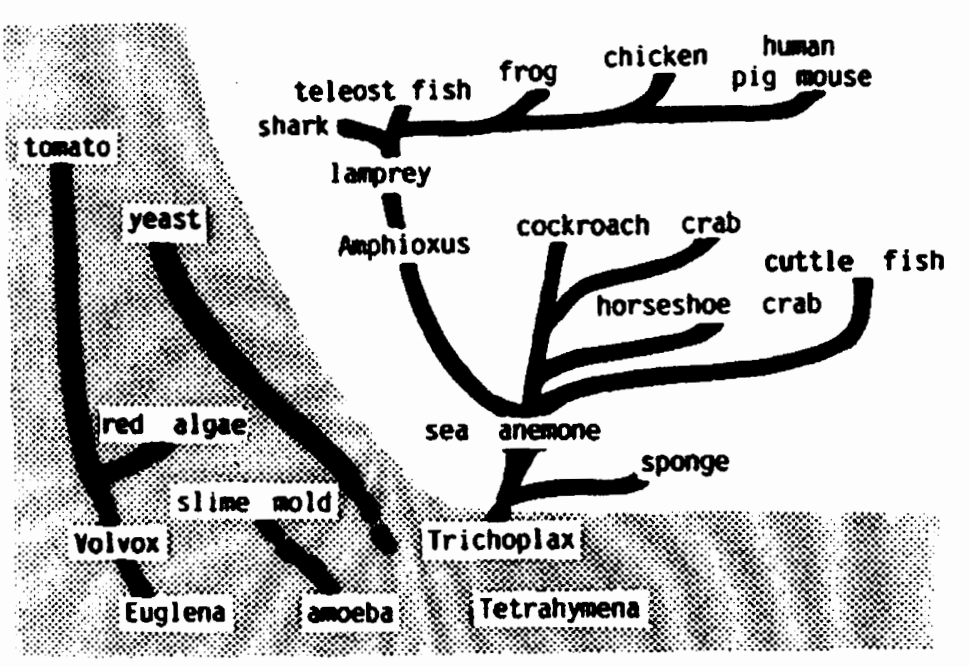

Fig. 21. Distribution of the $c$-src oncogene in living organisms. All organisms listed have been tested. $c$-src was found in all multicellular animals

to be possible based on the molecular findings of other laboratories that mutation, rearrangement. amplification. and demethylation can convert a silent oncogene to the transforming state. In contrast, our carcinogenesis studies show that the most important process involved in neoplasia in these animals is loss, impairment, or any other dysfunction of the regulatory gene system of the $T u$ oncogene. About 20 regulatory genes controlling the oncogene $T u$ at the gene level have been identified genetically and phenotypically. These genes comprise tissue-specific and compartment-specific (eye, mouth, etc.) regulatory genes (first to fifth experiments). Once the system of these regulatory genes controlling $T u$ is impaired, a chain of events is begun that can lead straight to neoplasia, but can also be interrupted by a genetic block of cell differentiation which protects the animal from the transforming activity of the oncogene. This protection mechanism can, however, easily be broken by promotion of cell differentiation (sixth experiment). If, finally, the cells are transformed, tumor growth can be stopped by terminal differentiation of the tumor cells exerted by the differentiation gene. Loss or impairment of the differentiation gene. then, leads definitely to neoplasia (seventh experiment). Our carcinogenesis experiments indicate that it is the regulatory genes (in the broadest sense) and not the oncogene itself that the carcinogens commonly act on, when they trigger neoplasia in Xiphophorus.

The inheritance and phenotypic expression of the genetically defined $T u$ oncogene parallels completely the expression of the molecularly defined $c$-src oncogene. Regardless of any future findings that might bring $T u$ substantially in relation to $c-s r c$ and/or any other $c$-onc, both $T u$ and $c$-src act, are regulated, and are inherited as if they were the same chromosomal gene of the natural gene pool of the Xiphophorus fish.

$c$-src has been found functioning in all taxonomic groups of multicellular animals ranging from mammals down to the sponges (Fig. 21) [16, 53], and intensive efforts are being made in many laboratories to determine whether a cellular oncogene, such as $c$-src, is capable of mediating neoplastic transformation like its viral counterpart [3, 54-59]. If this should be proven we suggest that all individuals of all metazoa are endowed with the capacity to develop neoplasia. Support for this idea comes from the fact that neoplasia is distributed - although sporadically - in all groups of multicellular animals [60-62]. Ubiquity of the oncogene in metazoa including humans on the one hand and the infrequent occurrence of neoplasia in all these organisms on the other hand raises the question of the mechanisms that protect the majority of the individuals of all metazoans from the action of their own oncogenes. The Xiphophorus model provides an opportunity to contribute to the study of this problem.

Acknowledgment. Thanks are due to Kristine Kruger for valuable help in the preparation of this paper. 


\section{References}

1. Anders F (1983) In: Neth R, Gallo RC, Greaves MF, Moore MAS, Winkler K (eds) Modern trends in human leukemia V. Springer, Berlin New York, pp 186-206 (Haematology and Blood Transfusion, vol 28)

2. Reddy EP, Reynolds RK, Santos E, Barbacid M (1982) Nature 300: 149-152

3. Tabin CJ, Bradley SM, Bargmann CI, Weinberg RA, Papageorge AG, Scolnick EM, Dhar R, Lowy DR, Chang EH (1982) Nature 300: 143-149

4. Taparowsky E, Suard Y, Fasano O, Shimizu K, Goldfarb M, Wigler M (1982) Nature 300: 762-764

5. Payne GS, Bishop JM, Varmus HE (1982) Nature 295:209-213

6. Dalla Favera $R$, Wong-Staal $F$, Gallo $R$ (1982) Nature 299:61-63

7. Schwab M, Alitalo K, Varmus HE, Bishop JM, George D (1983) Nature 303:497-501

8. Schimke RT (1984) Cancer Res 44: 1735-1742

9. Riggs AD, Jones PA (1983) Adv Cancer Res 40: $1-30$

10. Pimentel E (1985) Cancer Genet Cytogenet $14: 347-368$

11. Kallman KD (1975) Handb Genet 4:81-132

12. Anders F (1967) Experientia 23: I-10

13. Anders A, Anders F, Klinke K (1973) In: Schröder JH (ed) Genetics and mutagenesis of fish. Springer, Berlin New York, pp 33-63

14. Anders F, Anders A, Vielkind U (1974) Int Cancer Congr 11th Florence 3:305 (Abstr)

15. Anders A, Anders F (1978) Biochim Biophys Acta 516:61-95

16. Anders F, Schartl M, Barnekow A, Anders A (1984) Adv Cancer Res 42:191-275

17. Collet MS, Erikson RL (1978) Proc Natl Acad Sci USA 75:2021-2024

18. Barnekow A, Schartl M, Anders F, Bauer $H$ (1982) Cancer Res 42:2429-2433

19. Schartl M, Barnekow A, Bauer H, Anders F (1982) Cancer Res 42:4222-4227

20. Anders F, Schartl M, Barnekow A (1984) Natl Cancer Inst Monogr 65:97-109

21. Schartl M, Barnekow A (1984) Developmental Biology 105:415-422

22. Heil M (1984) Thesis, University of Giessen

23. Kollinger G, Schwab M, Anders F (1979) J Cancer Res Clin Oncol 95:239-246

24. Berthiaume L (1984) Virology 135: 10-19

25. Vielkind U, Schlage W, Anders F (1977) Z Krebsforsch 90:285-299

26. Ahuja MR, Schwab M, Anders F (1975) Experientia 31:296-297

27. Măueler W (1984) Thesis, University of Giessen

28. El-Zawahri MM, Hamdoon NT, Anders F (to be published) Cancer Genet Cytogenet
29. Hamdoon NT (1984) Thesis, University of Giessen

30. Ahuja MR, Schwab M, Anders F (1980) J Hered 71:403-407

31. Morizot DC, Sicliano MJ (1982) Genetics 102:539-566

32. Anders F, Schwab M, Scholl E (1981) In: Stich HF, San RHC (eds) Short-term tests for chemical carcinogens. Springer, Berlin New York, pp 399-407

33. Anders F, Schmidt CR, Herbert A, Anders A (1983) In: Prüfung von Chemikalien auf Kanzerogenität, Mutagenität und Teratogenităt. Ges. f. Strahlen- und Umweltforschung, München, pp 253-274

34. Vielkind J, Haas-Andela $\mathrm{H}$, Vielkind $U$, Anders F (1982) Mol Gen Genet 185: 379-389

35. Krontiris TG, Cooper GM (1981) Proc Natl Acad Sci USA 78: $1181-1184$

36. Perucho $M$, Goldfarb $M$, Shimizu K, Lama C, Fogh J, Wigler M (1981) Cell 27:467-476

37. Der CJ, Krontiris TG, Cooper GM (1982) Proc Natl Acad Sci USA 79:3637-3640

38. Anders F, Diehl H, Schwab $M$, Anders A (1979) In: Klaus SN (ed) Pigment cell; vol 4. Karger, Basel, pp 142-149

39. Anders F, Diehl H, Scholl E (1980) Linnean Soc Symp Ser 9:211-224

40. Constantinides PG, Taylor SM, Jones PA (1978) Dev Biology 66:57-71

41. Jones PA, Taylor SM (198I) Nucleic Acid Res 3:2933-2947

42. Vielkind U (1976) J Exp Zool 196: 197-204

43. Anders $A$, Dess $G$, Nishimura $S$, Kersten $H$ (to be published) In: Bagnara JT, Klaus $S$, Paul E, Schartl M (eds) Pigment Cell 1985

44. Kersten H (1982) In: Jaenicke L (ed) Biochemistry of differentiation and morphogenesis. Springer, Berlin New York, pp 116-119

45. Kersten $H(1983)$ in: Nass $G$ (ed) Recent results in cancer research: modified nucleosides and cancer. Springer, Berlin New York, pp 255-263

46. Nishimura S (1983) Prog Nucleic Acid Res Mol Biol 28:49-74

47. Katze JR, Beck WT. Cheng CS, McCloskey JA (1983) In: Nass G (ed) Recent results in cancer research: modified nucleosides and cancer. Springer, Berlin New York, pp 146 $-159$

48. Katze JR, Gündüz U, Smith DL, Cheng CS, McCloskey JA (1984) Biochemistry 23:1171 $-1176$

49. Sprinzl M, Gauss DH (1982) Nucleic Acids Res 10:r1-r55

50. Okada N, Nishimura S (1979) J Biol Chem 254:3062-3066

51. Kersten H, Schachner E. Dess G, Anders A, Nishimura S, Shindo-Okada N (1983) In: Curtis HC, Pfleiderer W, Wachter $H$ (eds) 
Biochemical and clinical aspects of pteridines. Walter de Gruyter, Berlin, pp 367-382

52. Nass $G$ (1983) Recent results in cancer research. Modified nucleosides and cancer. Springer, Berlin New York

53. Barnekow A, Schartl M (1984) Mol Cell Biol 4: $1179-1181$

54. Takeya $T$, Hanafusa $H$ (1982) J Virol 44: 12-18

55. de Klein $A$, van Kessel AG, Grosveld $G$, Bartram CR, Hagemeijer A, Bootsma D, Spurr NK, Heisterkamp N, Groffen J, Stephenson JR (1982) Nature 300:765-767

56. Duesberg P (1983) Nature 304:219-225
57. Bishop JM (1982) Sci Am 246:68-78

58. Weinberg RA (1983) Sci Am 249: 102-116

59. Hunter T (1984) Sci Am 251:60-69

60. Kraybill HF, Dawe CJ, Harshbarger JC, Tardiff RG (1977) Ann NY Acad Sci 298

61. Kaiser HE (1981) Neoplasms - comparative pathology of growth in animals, plants and man. Williams and Wilkins, Baltimore

62. Dawe CJ, Harshbarger JC, Kondo S, Sugimura T, Takayama S (1981) Phyletic approaches to cancer. Japan Scientific Societies Press, Tokyo

63. Schmiedel A (1984) Thesis. University of Giessen 